\title{
The Role of Microglia and Peripheral Monocytes in Retinal Damage after Corneal Chemical Injury
}

Eleftherios I. Paschalis, ${ }^{* \dagger \ddagger}$ Fengyang Lei, ${ }^{* \dagger \ddagger}$ Chengxin Zhou, ${ }^{* \dagger \ddagger}$ Vassiliki Kapoulea, ${ }^{* \dagger \ddagger}$ Aristomenis Thanos, ${ }^{\S}$ Reza Dana, ${ }^{*}$ Demetrios G. Vavvas, ${ }^{\S}$ James Chodosh, ${ }^{* \star}$ and Claes H. Dohlman ${ }^{* \dagger}$

From the Disruptive Technology Laboratory ${ }^{\ddagger}$ and the Angiogenesis Laboratory, ${ }^{\S}$ Department of Ophthalmology, ${ }^{*}$ Massachusetts Eye and Ear, Harvard Medical School, Boston; the Massachusetts Eye and Ear/Schepens Eye Research Institute, ${ }^{\dagger}$ Boston Keratoprosthesis Laboratory, Harvard Medical School, Boston, Massachusetts

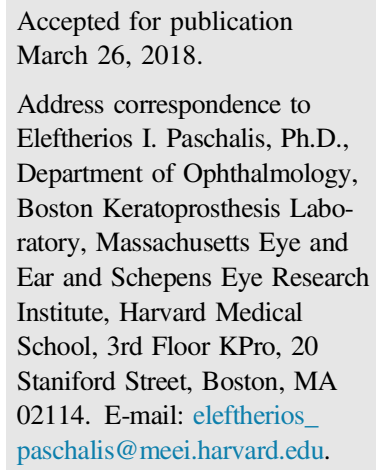

\begin{abstract}
Eyes that have experienced alkali burn to the surface are excessively susceptible to subsequent severe glaucoma and retinal ganglion cell loss, despite maximal efforts to prevent or slow down the disease. Recently, we have shown, in mice and rabbits, that such retinal damage is neither mediated by the alkali itself reaching the retina nor by intraocular pressure elevation. Rather, it is caused by the up-regulation of tumor necrosis factor- $\alpha$ (TNF- $\alpha$ ), which rapidly diffuses posteriorly, causing retinal ganglion cell apoptosis and $\mathrm{CD}_{4} 5^{+}$cell activation. Herein, we investigated the involvement of peripheral blood monocytes and microglia in retinal damage. Using $C X 3 C R 1^{+/ E G F P}:: C C R 2^{+/ R F P}$ reporter mice and bone marrow chimeras, we show that peripheral $C X 3 C R 1^{+} C D 45^{h i} C D 11 b^{+}$MHC-II ${ }^{+}$monocytes infiltrate into the retina from the optic nerve at 24 hours after the burn and release further TNF- $\alpha$. A secondary source of peripheral monocyte response originates from a rare population of patrolling myeloid $\mathrm{CCR}^{+}{ }^{+}$cells of the retina that differentiate into $\mathrm{CX} 3 \mathrm{CR} 1^{+}$macrophages within hours after the injury. As a result, $C X 3 C R 1^{+} C D 45^{l o} C D 11 b^{+}$microglia become reactive at 7 days, causing further TNF- $\alpha$ release. Prompt TNF- $\alpha$ inhibition after corneal burn suppresses monocyte infiltration and microglia activation, and protects the retina. This study may prove relevant to other injuries of the central nervous system. (Am J Pathol 2018, 188: 1580-1596; https://doi.org/10.1016/j.ajpath.2018.03.005)
\end{abstract}

Patients with ocular surface injuries (chemical, other traumas, surgery) often experience eventual vision loss from aggressive glaucoma, despite maximal antiglaucoma treatment. ${ }^{1-3}$ Our recent experimental work, in rabbits and mice, using alkali burn to the cornea as model, has demonstrated that substantial damage occurs not only to the anterior segment but also to the retina. ${ }^{4}$ The retinal ganglion cells (RGCs; the key cell layer for glaucoma) show apoptosis within 24 hours of the burn. ${ }^{5}$ This damage is neither because of a direct $\mathrm{pH}$ effect on the retina (the alkali is effectively buffered at the iris-lens level) nor is the damage secondary to intraocular pressure elevation. Rather, tumor necrosis factor (TNF)- $\alpha$ and other inflammatory cytokines, which become up-regulated in the anterior segment of the eye by the injury, diffuse posteriorly, and they rapidly cause activation of $\mathrm{CD} 45^{+}$cells and subsequent RGC apoptosis. ${ }^{4}$ The end result is a gradual decline in vision and eventual blindness, after months or years. ${ }^{1-3}$ The presumed critical role of TNF- $\alpha$ is supported by the strong neuroprotective effect on the retina of infliximab, a TNF- $\alpha$ inhibitor, when it is administered promptly after the burn. $^{4-6}$

Herein, the role of retinal CD $45^{+}$cells and, in particular, the retinal microglia and blood-derived monocytes/macrophages was explored in the pathogenesis of the retinal degeneration after alkali injury to the cornea. Microglia and macrophages are both implicated in most neurodegenerative disorders of the central nervous system (CNS) and brain injuries. $^{7-11}$ Macrophage infiltration and microglia

Supported by Boston Keratoprosthesis Research Fund, Massachusetts Eye and Ear, the Eleanor and Miles Shore Fund, the Massachusetts Lions Eye Research Fund, Research to Prevent Blindness (New York, NY) unrestricted grant to the Department of Ophthalmology, Harvard Medical School, and NIH National Eye Institute core grant P30EY003790.

E.I.P. and F.L. contributed equally to this work.

Disclosures: None declared. 

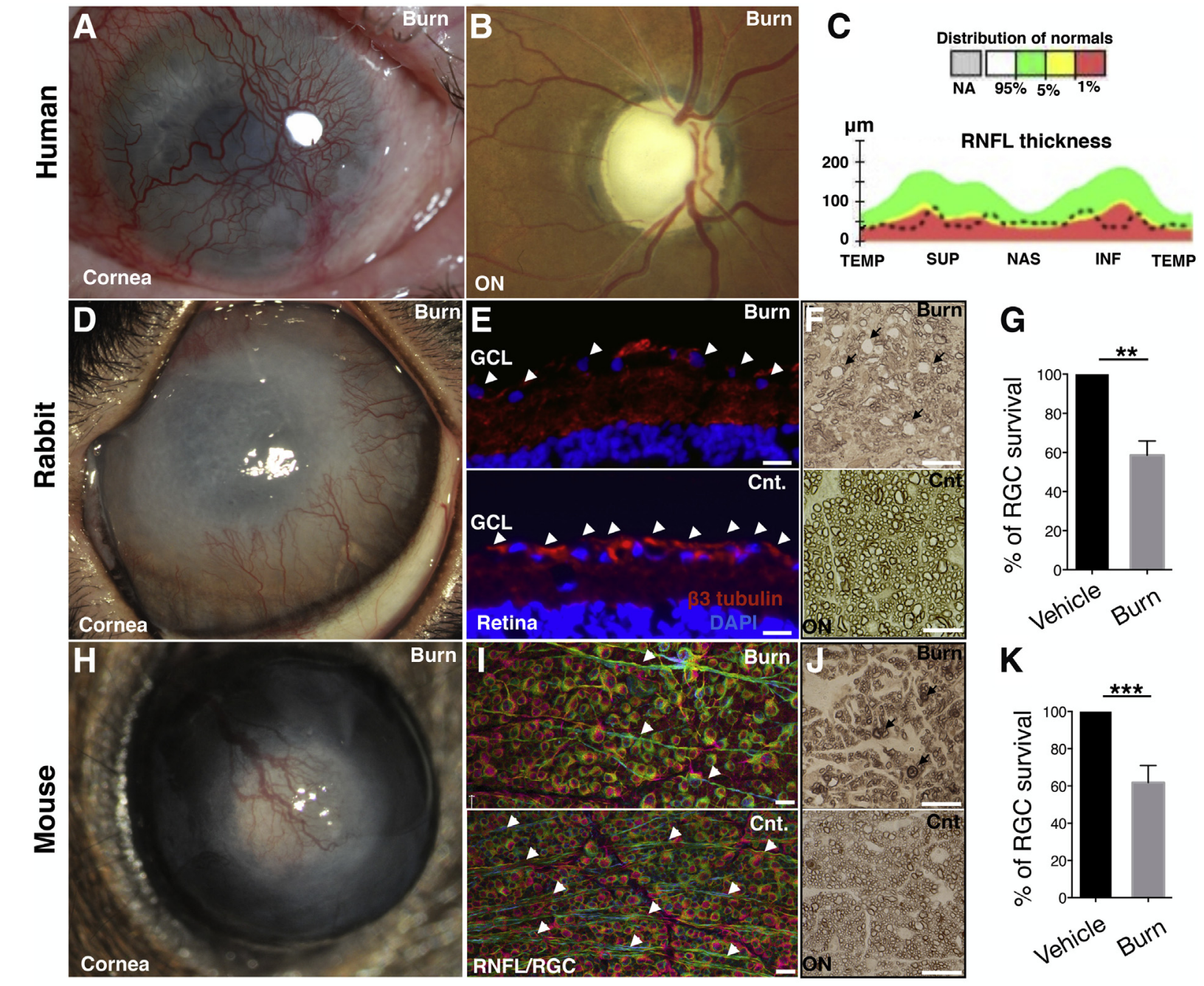

$\mathbf{L}$

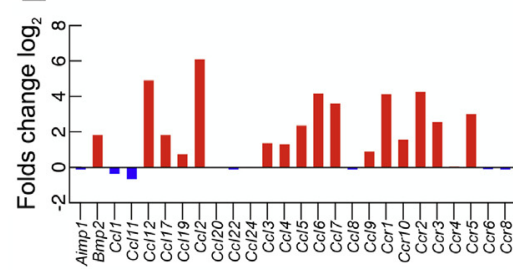

PCR retina
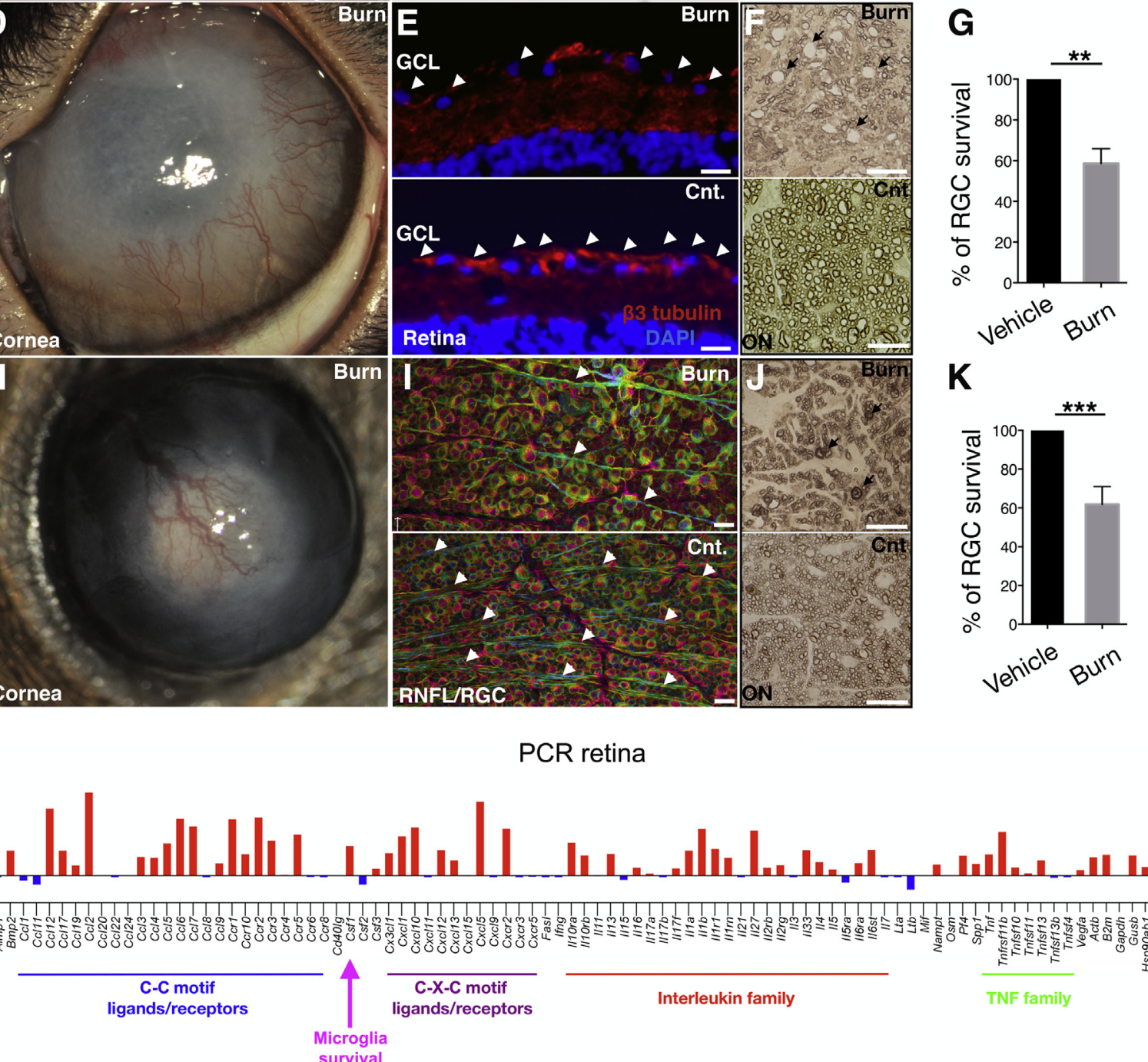

Figure 1 Corneal alkali burn causes retinal damage in humans and animals. A: Digital image of a human cornea after alkali burn presented with extensive neovascularization and conjunctivalization. B: Fundus digital imaging of the optic nerve (ON) reveals end-stage glaucoma associated with advanced $0 \mathrm{~N}$ cupping and parlor. C: In vivo optical coherence tomography confirms significant loss of retinal nerve fiber layer (RNFL) thickness (dotted black line) compared with normal agematched controls (green section). D: Digital image of a rabbit cornea after alkali burn with extensive neovascularization and conjunctivalization. E: Immunohistochemical analysis of rabbit retina using $\beta$ III-tubulin after corneal alkali burn (top panel) and of control eye (bottom panel) shows significant reduction in RNFL thickness in the burned eye compared with control retina (white arrowheads denote ganglion layer cells). $\mathbf{F}$ and $\mathbf{J}$ : P-phenylenediamine staining of rabbit and mouse ONs after corneal alkali burn (top panel) and of control eye (bottom panel) shows significant axonal degeneration in burned eyes (black arrows). G: Corresponding $40 \%$ of retinal ganglion cell (RGC) loss. H: Digital image of a mouse cornea after alkali burn with extensive neovascularization and conjunctivalization. I: Immunohistochemical analysis of flat mount mouse retinas using BIII-tubulin marker after corneal alkali burn (top panel) and of control eye (bottom panel) shows significant loss of RNFL density (white arrowheads). K: Corresponding 40\% of RGC loss assessed by Brn3a marker. L: Microarray RNA analysis in mouse retinas 24 hours after the burn shows significant up-regulation (more than twofold $\log _{2}$ ) of C-C and C-X-C motif genes involved in monocyte recruitment, colony stimulating factor 1 gene required for microglia survival, and inflammatory genes of the IL and tumor necrosis factor (TNF)- $\alpha$ families. $\mathbf{G}$ and $\mathbf{K}$ : Independent $t$-test was used. $n=3$ (G, $\mathbf{K}$, and $\mathbf{L}$ ). ${ }^{* *} P<0.01,{ }^{* *} P<0.001$. Scale bars: $20 \mu \mathrm{m}$ (E and $\left.\mathbf{I}\right) ; 10 \mu \mathrm{m}(\mathbf{F}$ and $\mathbf{J})$. Cnt., control; GCL, ganglion cell layer; INF, inferior (refers to different retinal segments); NA, not applicable; NAS, nasal; SUP, superior; TEMP, temporal. 
A

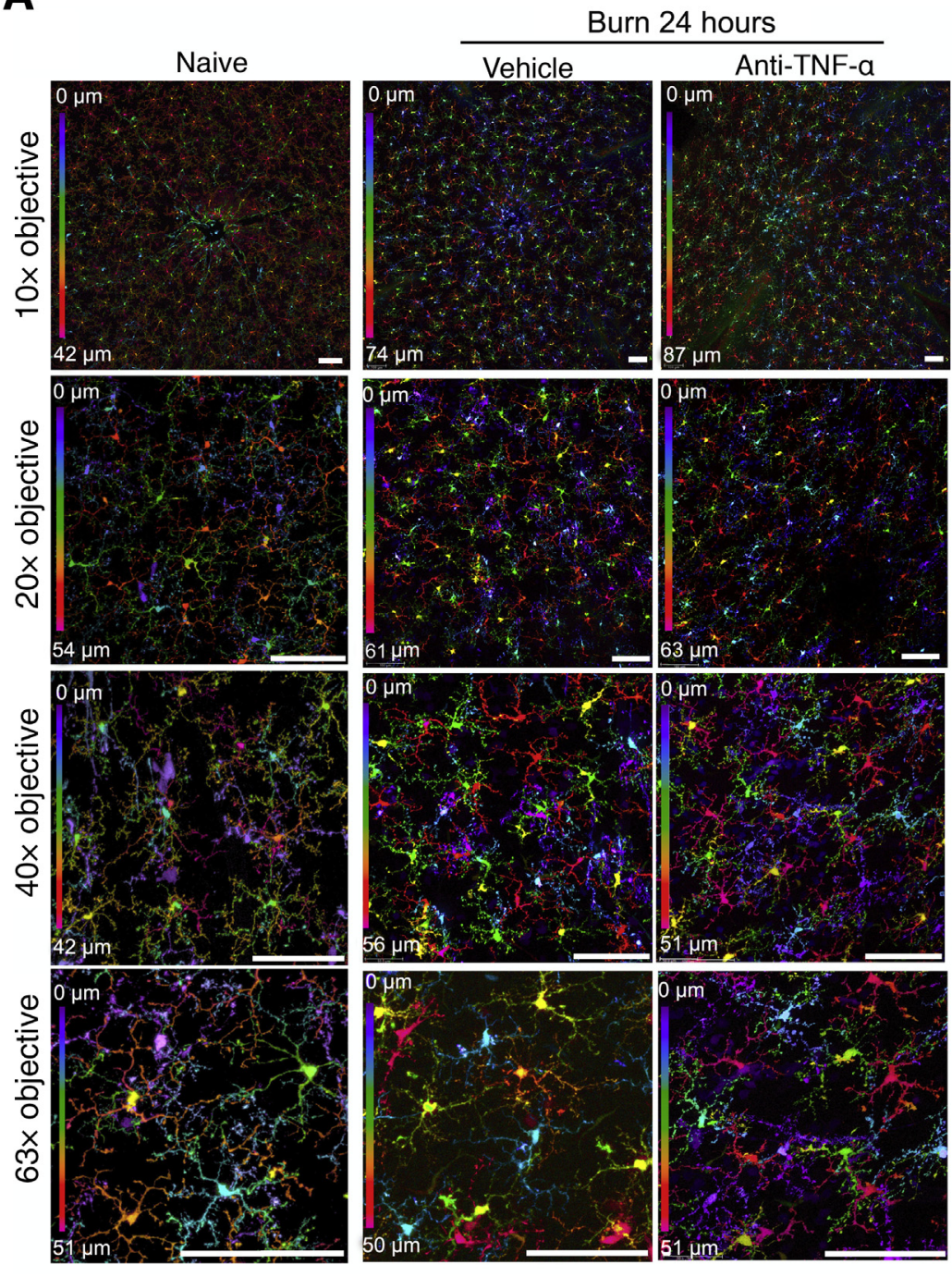

B

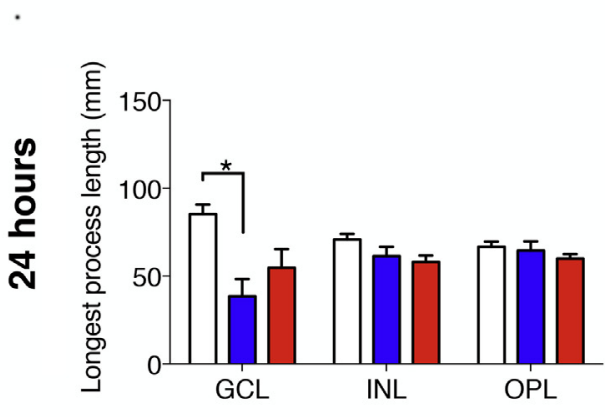

$\square$ Naive

$\square$ Anti-TNF-a
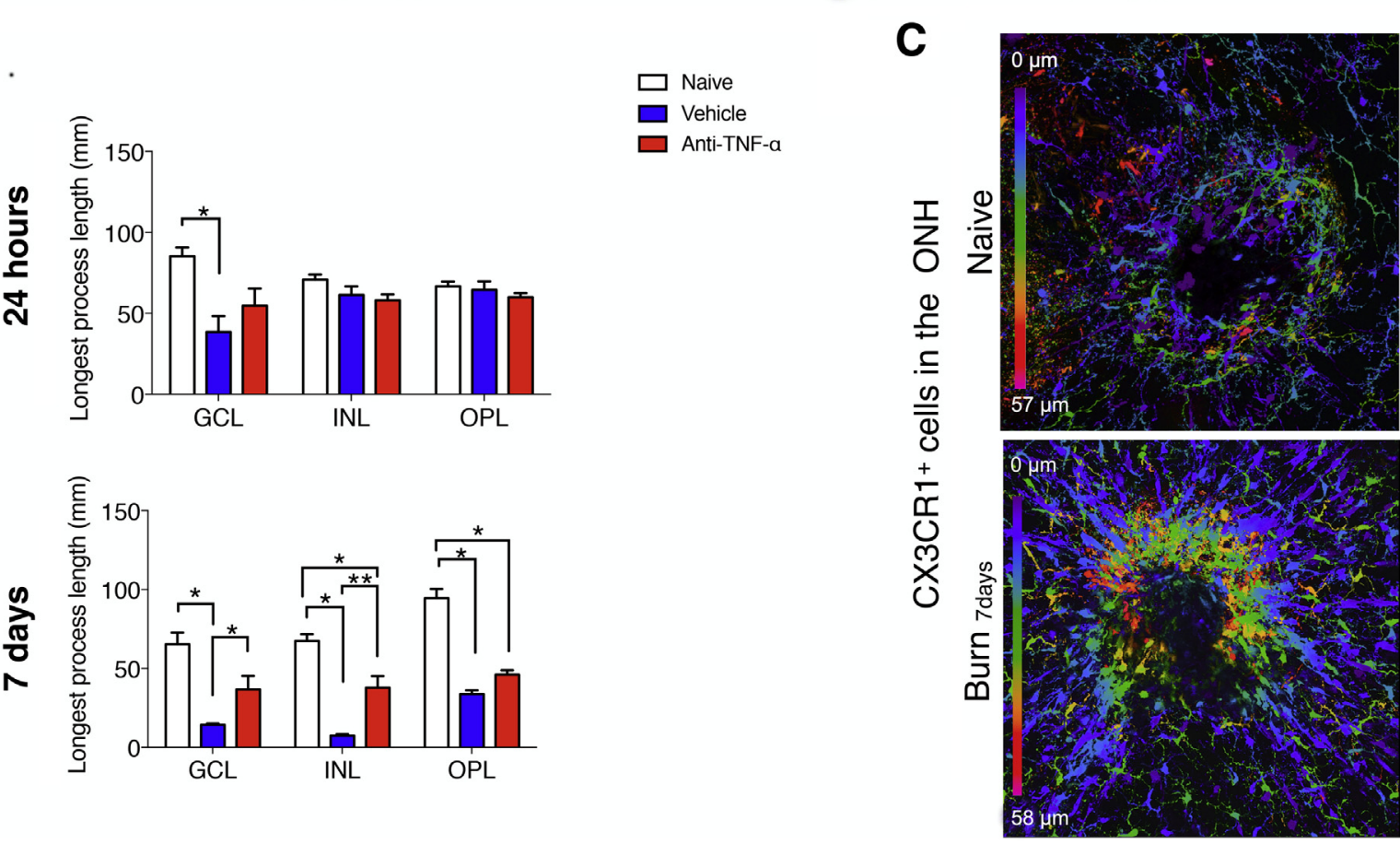
activation in the CNS are both signs of pathology, ${ }^{12-15}$ and microglia activation precedes glaucomatous damage in ocular hypertension models. ${ }^{16,17}$ Both microglia and macrophages can release TNF- $\alpha$ on activation ${ }^{18}$ and mediate RGC apoptosis. ${ }^{819}$ TNF inhibition has been shown to protect the retina in various ocular injury models. ${ }^{4-6,20}$ In this study, reporter mice and bone marrow chimeras were used to study the role of microglia and peripheral monocytes in retinal degeneration after corneal alkali burn. The therapeutic role of TNF- $\alpha$ inhibition, as a prelude to potential human clinical application, was further explored. ${ }^{21}$

\section{Materials and Methods}

\section{Study Approval}

All animal experiments were reviewed and approved by the Animal Care Committee of the Massachusetts Eye and Ear Infirmary and were performed in accordance with the Association for Research in Vision and Ophthalmology.

\section{Mouse Model of Alkali Burn}

All animal-based procedures were performed in accordance with the Association for Research in Vision and Ophthalmology Statement for the Use of Animals in Ophthalmic and Vision Research and the NIH's Guide for the Care and Use of Laboratory Animals. ${ }^{22}$ This study was approved by the Animal Care Committee of the Massachusetts Eye and Ear Infirmary (Boston, MA). C57BL/6J, B6.129P-Cx3 $\mathrm{cr}^{\text {tmlLitt }^{\text {J }} / \mathrm{J}}$ (CX3CR1 ${ }^{\text {EGFP/EGFP }}$ Stock 005582), B6.129(Cg)-Ccr2 ${ }^{\text {tm2.1llfc } / \mathrm{J}}$ (CCR2 $2^{\text {RFP/RFP }}$ Stock 017586), B6.129-Tnfrsfla ${ }^{\text {tmlMak } / J}$ (TNFR1 $^{-1-}$ Stock 002620), B6.129S2-Tnfrsflb $b^{\text {tmlMwm } / \mathrm{J}}$ (TNFR2 $^{-1-}$ Stock 002818), and B6.129S-Tnfrsfla ${ }^{\text {tmllmx }}$ Tnfrsfl $b^{\text {tm IImx } / J}$ (TNFR1/2 ${ }^{-1-}$ Stock 003243) mice were obtained from the Jackson Laboratory (Bar Harbor, ME). Mice between the ages of 6 and 12 weeks were used for this study. This model of alkali chemical burn is based on our previously published study. ${ }^{4}$ In brief, mice were anesthetized using $60 \mathrm{mg} /$ $\mathrm{kg}$ ketamine and $6 \mathrm{mg} / \mathrm{kg}$ xylazine, and deep anesthesia was confirmed by a toe pinch test. Proparacaine hydrochloride USP $0.5 \%$ (Bausch and Lomb, Tampa, FL) eye drop was applied to the cornea, and after 1 minute, was carefully dried with a Weck-Cel (Beaver Visitec International, Inc., Waltham, MA). A 2-mm diameter filter paper was soaked into $1 \mathrm{~mol} / \mathrm{L} \mathrm{NaOH}$ solution for 10 seconds, dried of excess $\mathrm{NaOH}$ by a single touch on a paper towel, and applied onto the mouse cornea for 20 seconds. Complete adherence of the filter paper on the corneal surface was confirmed by gentle pushing of the perimeter using forceps. After the filter paper was removed, prompt irrigation with sterile saline for 10 seconds was applied using a $50-\mathrm{mL}$ syringe with a 25 gauge needle. The mouse was then placed on a heating pad, positioned laterally, and the eye irrigated for another 15 minutes at low pressure using sterile saline. Buprenorphine hydrochloride $(0.05 \mathrm{mg} / \mathrm{kg}$; Buprenex Injectable; Reckitt Benckiser Healthcare Ltd, Slough, UK) was administered subcutaneously for pain management. A single drop of topical Polytrim antibiotic was administered after the irrigation (polymyxin B/trimethoprim; Bausch \& Lomb Inc., Bridgewater, NJ). Mice were kept on the heating pad until fully awake.

\section{Treatment of Burns}

Anti-TNF- $\alpha$ treatment was performed 15 minutes after the burn with an i.p. injection $(6.25 \mathrm{mg} / \mathrm{kg}$ reconstituted in normal saline) of infliximab (Janssen Biotech, Horsham, PA). Wild-type naive mice were used as controls. The contralateral nonburned eye was used as internal control. Human IgG1 $\kappa$ isotype antibody (GeneTex, Irvine, CA) was used as vehicle control $(6.25 \mathrm{mg} / \mathrm{kg}$; i.p.), when appropriate, and no treatment as no-treatment control to simulate the clinical outcomes of patients who do not receive treatment after burn.

\section{Tissue Preparation for Immunohistochemically Frozen Sections}

After the alkali burn, eyes were enucleated at predetermined time points and processed using OCT (Tissue Tek, 4583; VWR, Randor, PA) compound. Multiple sagittal sections of approximately $10 \mu \mathrm{m}$ in thickness were obtained from the center and the periphery of the globe. Sectioned tissues were transferred to positive charged glass slides (Superfrost Plus, $75 \times 25 \mathrm{~mm}, 1-\mathrm{mm}$ thickness; VWR) and stored at $-80^{\circ} \mathrm{C}$ for further processing.

\section{Tissue Preparation for Flat Mount Imaging}

After the alkali burn, eyes were enucleated at predetermined time points and fixed in $4 \%$ paraformaldehyde (SigmaAldrich, St. Louis, MO) solution for 1 hour at $4^{\circ} \mathrm{C}$. The cornea and retina tissue were carefully isolated using

\footnotetext{
Figure 2 Corneal alkali burn causes CX3CR1 ${ }^{+}$cell activation in the retina. A: Confocal images of flat-mounted retinas of CX3CR1 ${ }^{+/ E G F P}$ reporter mice 24 hours and 7 days after corneal alkali burn. Cells are color-depth coded on the basis of their position within the retina layers. Blue indicates cells in the ganglion cell layer $(\mathrm{GCL} ; 0 \mu \mathrm{m})$, red indicates cells in the outer plexiform layer $(\mathrm{OPL})$, and intermediate colors indicate cells between the GCL and OPL. Color bar translates color to $\mu \mathrm{m}$. B: Morphometric analysis of $\mathrm{CX} 3 \mathrm{CR} 1^{+}$cells was performed in three distinct retina layers: the $\mathrm{GCL}$, inner nuclear layer (INL), and OPL. The longest process length measured from the edge of the cell body (in $\mu \mathrm{m}$ ) was used as a morphometric descriptor of CX3CR1 ${ }^{+}$cell activation. A and B: At 24 hours after the burn, CX3CR1 ${ }^{+}$ cells in the GCL start to become amoeboid, exhibiting significant reduction in processes length. CX3CR1 ${ }^{+}$cells in the INL and OPL are not affected. Anti-tumor necrosis factor (TNF)- $\alpha$ treatment preserves cell ramification in the GCL. C: At 7 days, CX3CR1 ${ }^{+}$cells accumulate around the outer segment of the optic nerve head $(\mathrm{ONH})$ and align to the direction of the retina nerve fiber layer. Also, $\mathrm{CX} 3 \mathrm{CR} 1^{+}$cells in all retinal layers became more amoeboid, with significant shortening of the cell processes. Anti-TNF- $\alpha$ treatment significantly reduces CX3CR1 ${ }^{+}$cell amoeboid transformation in all retinal layers and reduces cell accumulation around the $0 \mathrm{NH}$. B: Multiple comparisons using Holm-Sidak method. $n=3$ per group (B). ${ }^{*} P<0.05,{ }^{*} P<0.01$. Scale bars $=100 \mu$ m (A). Original magnification, $\times 40$ (C).
} 
A

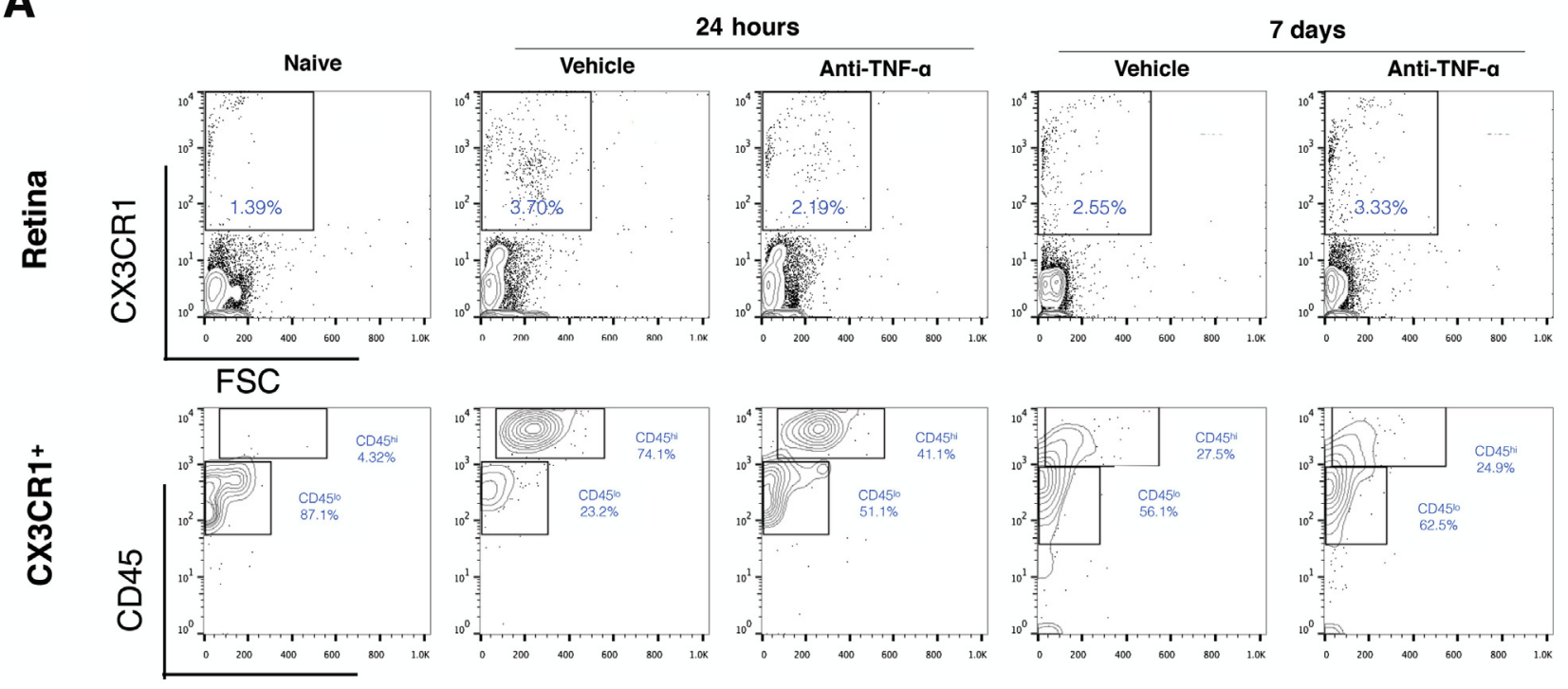

FSC
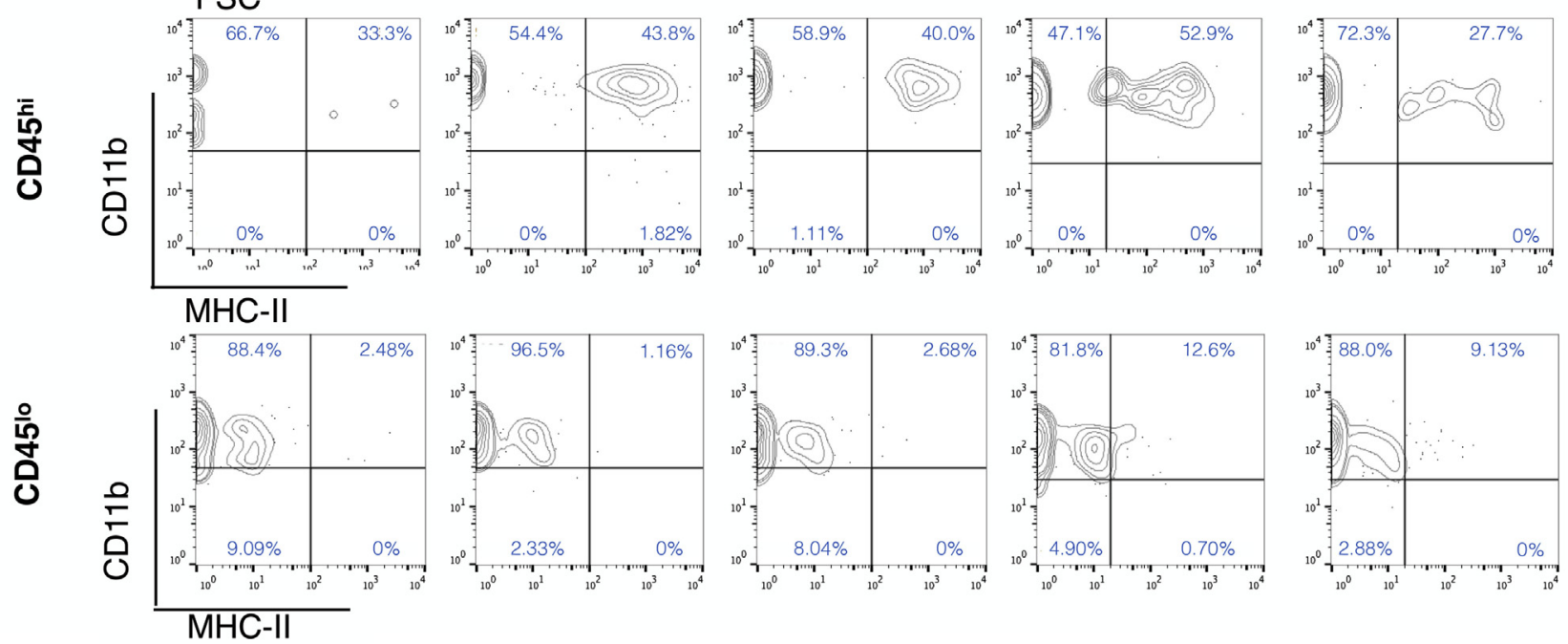

B
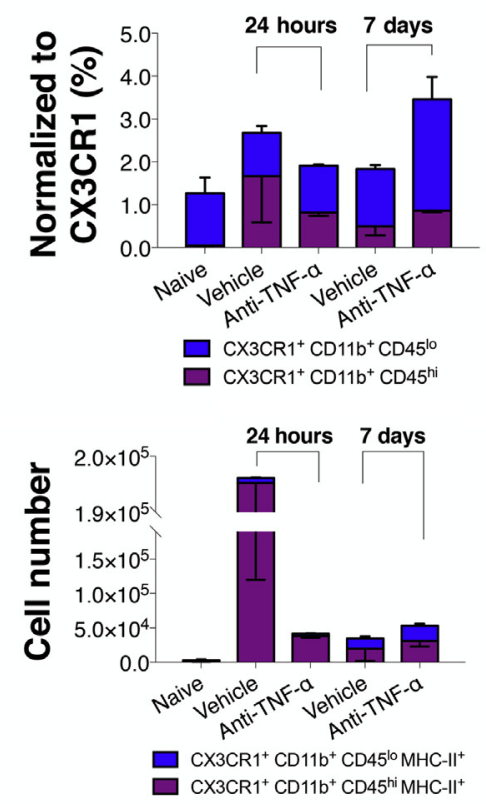

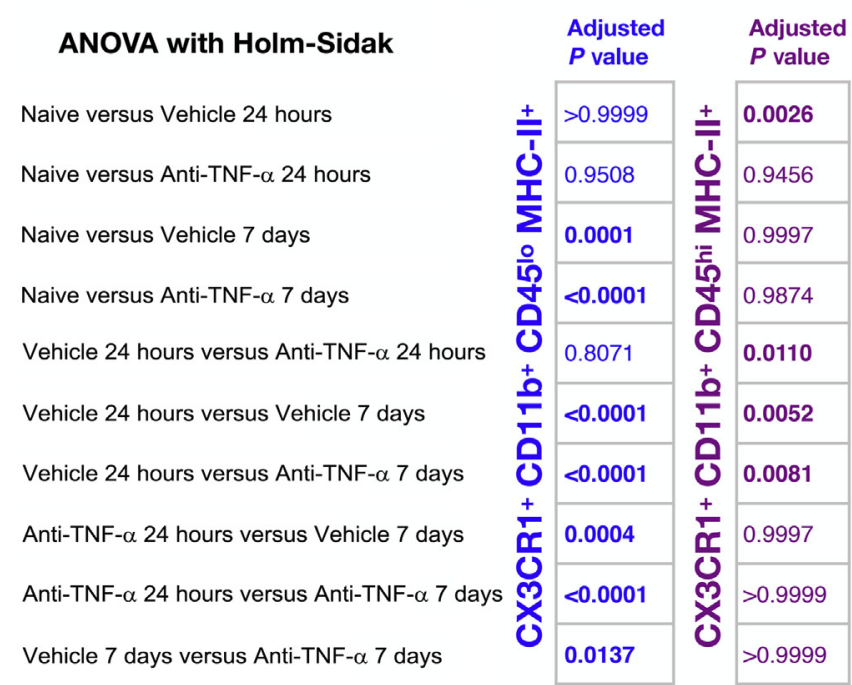


microsurgical techniques and washed three times for 5 minutes in phosphate-buffered saline (PBS) solution (Sigma-Aldrich) at $4^{\circ} \mathrm{C}$. The tissues were then blocked using 5\% bovine serum albumin (Sigma-Aldrich) and permeabilized using $0.3 \%$ Triton-X (Sigma-Aldrich) for 1 hour at $4{ }^{\circ} \mathrm{C}$. The specific antibody was added in blocking solution, incubated overnight at $4^{\circ} \mathrm{C}$, and then washed three times for 10 minutes with $0.1 \%$ Triton- $X$ in PBS. Tissues were transferred from the tube to positive charged glass slides using a wide piper tip with the concave face upwards. Four relaxing incisions from the center to the periphery were made to generate four flat tissue quadrants. VECTRASHIELD mounting medium (H-1000; Vector Laboratories, Burlingame, CA) was placed over the tissue, followed by a coverslip.

\section{TUNEL Labeling and Quantitation of DNA Fragmentation}

After the alkali burn, eyes were enucleated and cryosectioned. Terminal deoxynucleotidyl transferase-mediated dUTP nick-end labeling (TUNEL) labeling was performed using a Roche TUNEL kit (12156792910; Roche, Indianapolis, IN), as previously published..$^{5}$ Mounting medium with DAPI (UltraCruz; sc-24941; Santa Cruz Biotechnology, Dallas, TX) was placed over the tissue, followed by a coverslip. Images were taken with an epifluorescent microscope (Zeiss Axio Imager M2; Zeiss, Oberkochen, Germany), using the tile technique. DAPI signal (blue) was overlayed with Texas red (TUNEL ${ }^{+}$cells) and quantified using ImageJ software version 1.5s (http://imagej.nih.gov/ij; $\mathrm{NIH}$, Bethesda, MD) to measure the number of TUNEL ${ }^{+}$ cells overlapping with DAPI in the areas of interest. All experiments were performed in triplicate.

\section{Immunolocalization of TNF- $\alpha$ and $\beta 3$-Tubulin Protein Expression}

After the alkali burn, eyes were enucleated at predetermined time points and processed for frozen section, as described above. Sectioned tissues were fixated onto the glass slides using $4 \%$ paraformaldehyde for 15 minutes at room temperature. The slides were then washed three times for
5 minutes in PBS and dried for paraffin boundary marking using paraffin pen.

TNF- $\alpha$

Tissues were blocked with $5 \%$ bovine serum albumin and incubated at $4^{\circ} \mathrm{C}$ overnight using 1:100 dilution of monoclonal anti-mouse fluorescein isothiocyanate conjugated antibody (NBP1-51502; Novus Biologicals, Littleton, CO). Tissues were washed three times for 5 minutes in PBS at room temperature and mounted using either VECTASHIELD or mounting medium with DAPI, and covered with a coverslip.

\section{$\beta 3$-Tubulin}

Tissues were blocked with $5 \%$ bovine serum albumin in PBS $+0.1 \%$ Tween-20 for 30 minutes at room temperature. Overnight incubation at $4{ }^{\circ} \mathrm{C}$ was performed using conjugated mouse monoclonal antibody (NL557; R\&D Systems, Minneapolis, MN) at 1:100 dilution. Tissues were washed three times for 5 minutes in PBS at room temperature and mounted using either VECTASHIELD or mounting medium with DAPI, and covered with a coverslip.

\section{Retinal Flat Mount Preparation for Microglia/ Macrophage and Nerve Fiber Layer Assessment}

Alkali burned eyes from CX3CR1 $1^{+/ E G F P}$ mice were enucleated at different time points, and whole retinas and corneas were processed with anti-neuron-specific $\beta$-III tubulin (NL557; R\&D Systems) conjugated antibody in 1:80 dilution. The tissues were prepared for flat mount, as described above, and imaged using a confocal microscope (Leica SP-5; Leica Microsystems Inc., Buffalo Grove, IL). Images were taken at $10 \times, 20 \times, 40 \times$, and $63 \times$ objective lenses using Z-stack of 0.7-, 0.6-, 0.4-, and 0.3- $\mu \mathrm{m}$ step, respectively. Image processing with ImageJ version $1.5 \mathrm{~s}$ was used to obtain maximum and average projections of the $z$ axis, color depth maps, and three-dimensional volumetric images. Retinal microglia/macrophage cells were quantified by layer-bylayer technique, total Z-stack projection technique, and volumetric three-dimensional analysis. Retinal nerve fiber layer (RNFL) was quantified by using Z-stack projection and binary image conversion or by orthogonal transverse twodimensional cuts of the nerves and area measurements.

\footnotetext{
Figure 3 Activated retinal CX3CR1 $1^{+}$cells have microglia and macrophage signatures. A, B, and D: Biochemical assessment of CX3CR1 ${ }^{+}$cells using flow cytometry. CX3CR1 ${ }^{+}$CD11 $b^{+}$cells divided into macrophages (CD45 hi) and microglia (CD45 ${ }^{\text {lo }}$ ). Major histocompatibility complex (MHC)-II expression was used as a metric of cell activation. Naive eyes express predominantly CD45 $5^{\text {lo }}(90 \%)$, with only $4 \%$ of the CX3CR1 $1^{+}$cells expressing CD $45^{\text {hi }}$. None of the CD45 cell populations express MHC-II. Twenty-four hours after the burn, the percentage of $\mathrm{CX} 3 \mathrm{CR} 1^{+} \mathrm{CD} 11 \mathrm{~b}^{+} \mathrm{CD} 45^{\text {hi }}$ cells in the retina increases with concomitant increase in MHC-II expression. Seven days after the burn, CX3CR1 ${ }^{+}$CD11 $\mathrm{b}^{+} \mathrm{CD} 45^{\text {hi }}$ population decreases with concomitant reduction in MHC-II expression. At the same time, the percentage of $\mathrm{CX} 3 \mathrm{CR} 1^{+} \mathrm{CD} 11 \mathrm{~b}^{+} \mathrm{CD} 45^{\text {lo }}$ remains unchanged, but the number of $\mathrm{MHC}-\mathrm{II}^{+}$cells increases. Treatment with monoclonal anti-tumor necrosis factor (TNF)- $\alpha$ antibody significantly reduces the number of $\mathrm{CX} 3 \mathrm{CR} 1^{+} \mathrm{CD} 11 \mathrm{~b}^{+} \mathrm{CD} 45^{\mathrm{hi}} \mathrm{MHC}-\mathrm{II}^{+}$cells in the retina, but it has no effect on the number of $\mathrm{CX} 3 \mathrm{CR} 1^{+} \mathrm{CD} 11 \mathrm{~b}^{+} \mathrm{CD} 45^{\mathrm{lo}} \mathrm{MHC}-\mathrm{II}^{+}$cells. At 7 days, anti-TNF- $\alpha$ treatment increases the percentage of $\mathrm{CX} 3 \mathrm{CR} 1^{+} \mathrm{CD} 45^{\circ 0} \mathrm{CD} 11 \mathrm{~b}^{+}$and their

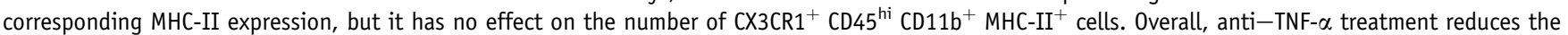
infiltration of $\mathrm{CX} 3 \mathrm{CR} 1^{+} \mathrm{CD} 11 \mathrm{~b}^{+} \mathrm{CD} 45^{\text {hi }}$ cells in the retina and prevents MHC-II expression by these cells. C: Statistical comparisons of the number of CX3CR1 ${ }^{+}$

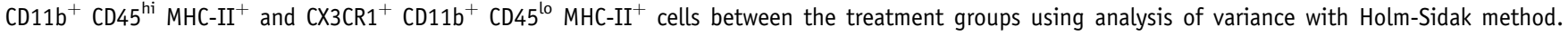
Statistically significant values $(\leq 0.05)$ are shown in bold. $n=3$ in all groups. ANOVA, analysis of variance; FSC, forward scatter.
} 


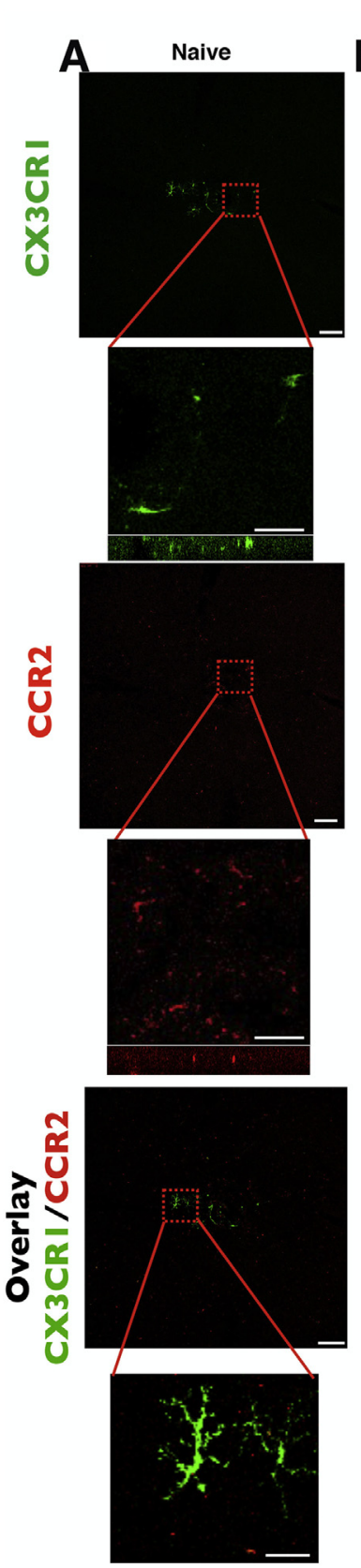

10 weeks after BMT

$\mathbf{F}$

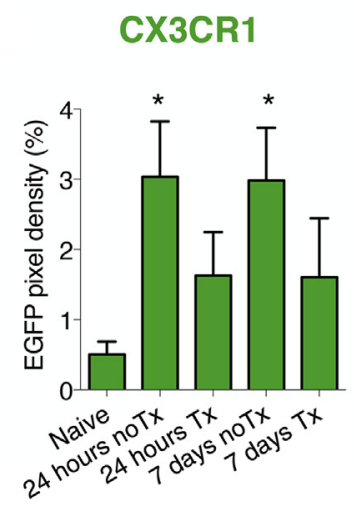

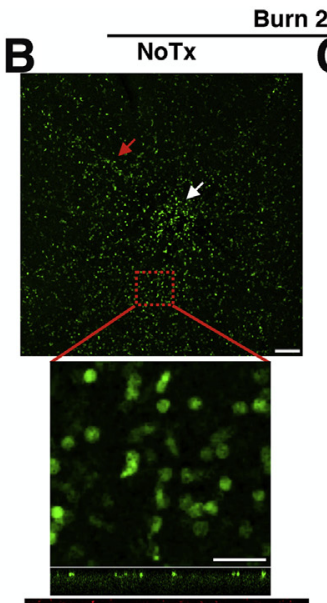
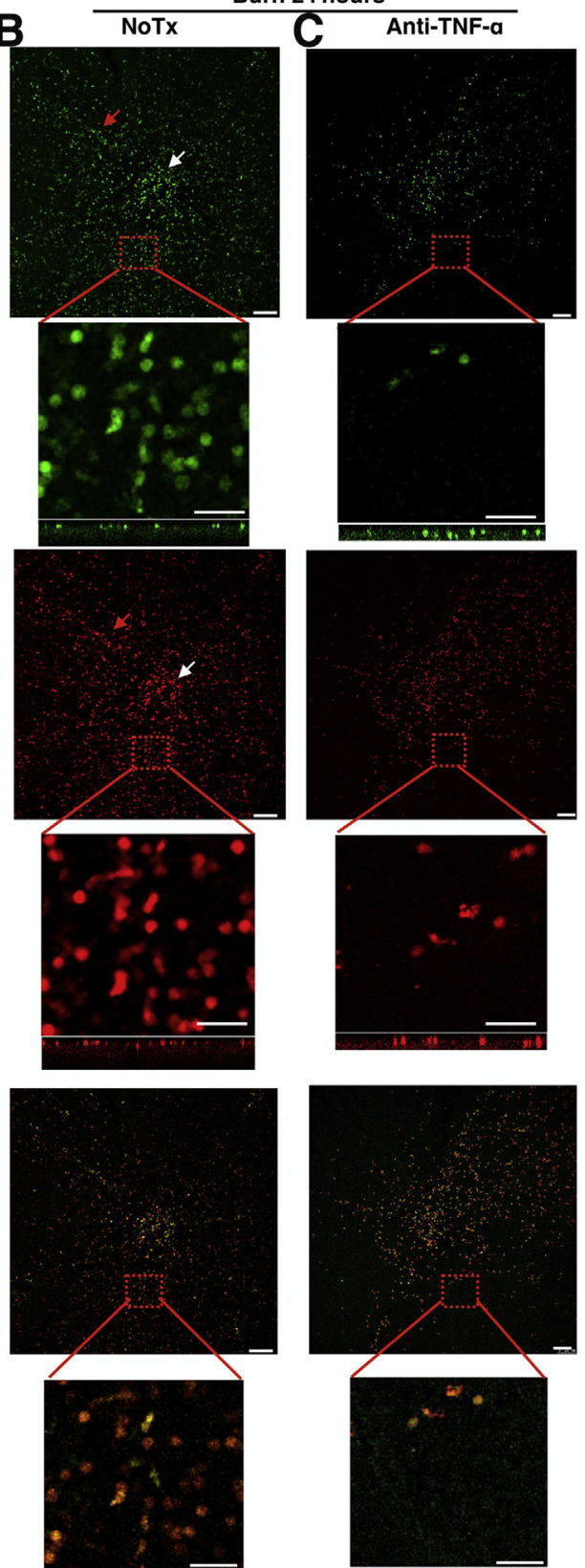

10 weeks after BMT
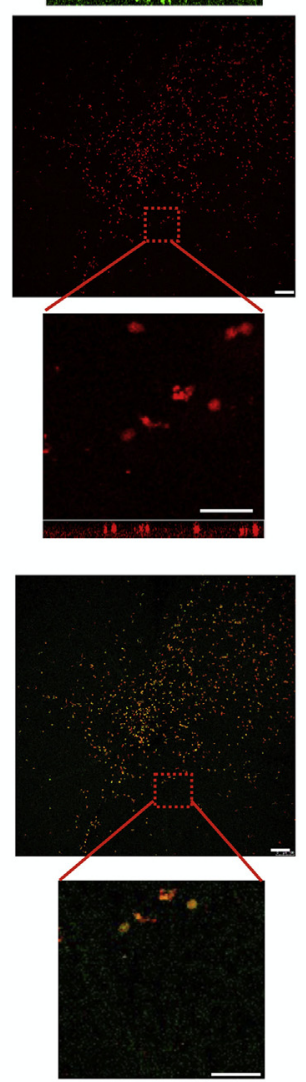

10 weeks after BMT

H
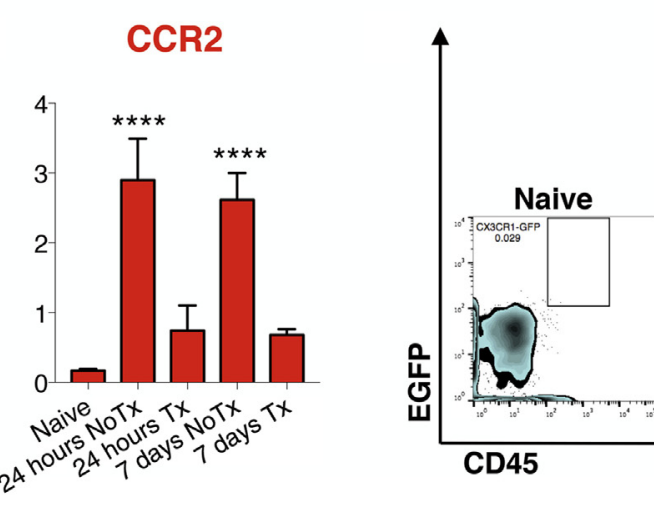
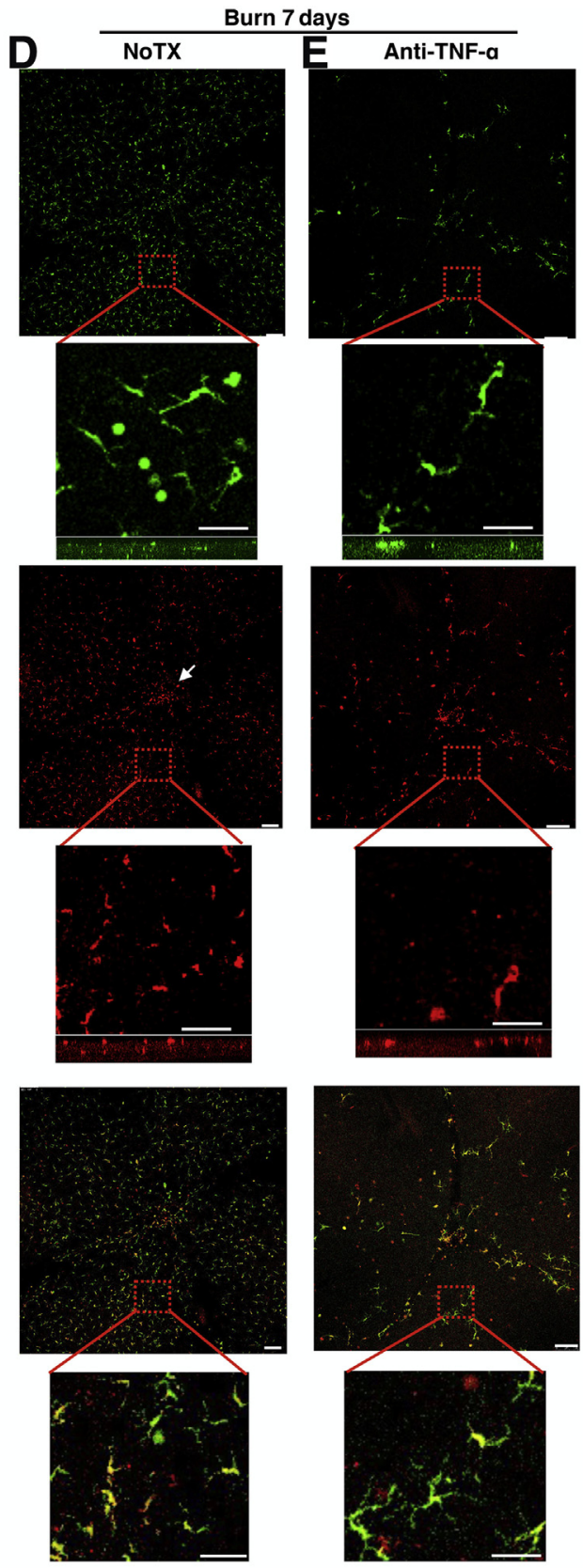

11 weeks after BMT

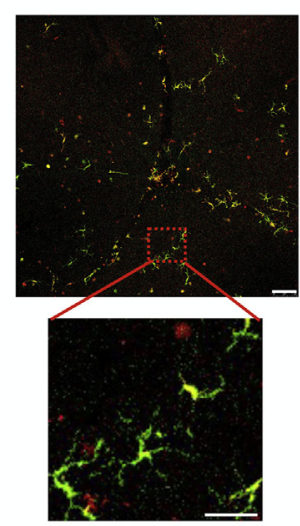

11 weeks after BMT

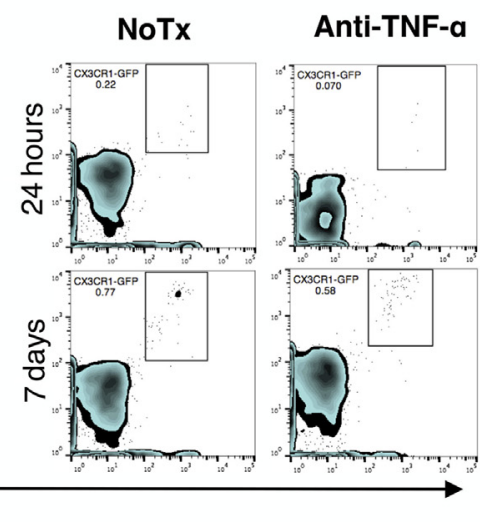




\section{PCR Array for Measuring Proinflammatory Cytokine Expression}

After the alkali burn, eyes were harvested at predetermined time points. Corneal and retinal tissues were surgically dissected, placed in cryovials, and rapidly frozen in liquid nitrogen. RNA isolation was performed using RNeasy Mini Kit (74106; Qiagen, Valencia, CA) for retinas. RNA quantification was performed using a nanodrop spectrophotometer (Nanodrop 2000; Thermo Fisher Scientific, Waltham, MA), and each sample was normalized before cDNA synthesis. cDNA synthesis was performed using superscript III (18080044; Invitrogen, Carlsbad, CA). One microliter of cDNA was used in each RT-PCR. RT ${ }^{2}$ Profiler PCR Array Mouse Inflammatory Cytokines \& Receptors Kit (PAMM_011Z; Qiagen, San Diego, CA) was used to evaluate retinal inflammation after the ocular alkaline injury. The assay was performed per manufacturer's instruction, and data were analyzed by using Qiagen's data analysis web portal.

\section{Bone Marrow Chimera Model}

C57BL/6J mice were myelodepleted with three i.p. injections of busulfan (Sigma-Aldrich; $35 \mathrm{mg} / \mathrm{kg}$ ) 7, 5, and 3 days before bone marrow transfer. CX3CR $1^{+/ \text {EGFP }}:: \mathrm{CCR} 2^{+/ \text {RFP }}$ or only CX3CR $1^{+/ E G F P}$ bone marrow cells $\left(5 \times 10^{6}\right.$ total bone marrow cells) were transferred to the myelodepleted C57BL/ $6 \mathrm{~J}$ mice through tail vein injection 1 month before corneal alkali burn. Bactrim (trimethoprim/sulfamethoxazole, 80/400 $\mathrm{mg}$, respectively) was resuspended in $400-\mathrm{mL}$ drinking water and given ad libitum for 15 days after busulfan treatment.

\section{Assessment of Immune Cell Activation/Infiltration in the Retina by Flow Cytometry}

Eyes were harvested at various, predetermined, time points. Retinas were isolated surgically and processed for flow cytometry using Collagenase Type I and Papain Dissociation System (Worthington Biochemical Corp., Lakewood, NJ), respectively. Thy1.1-phosphatidylethanolamine antibody (BioLegend, San Diego, CA) was used to identify RGCs, whereas retinal microglia/macrophage cells were detected as enhanced green fluorescent protein $(\mathrm{EGFP})^{+}$population in $\mathrm{CX} 3 \mathrm{CR} 1^{+/ E G F P}$ mice. Different fluorescent CD45 (clone 104), CD11b (clone M1/70), I-A/I-E [major histocompatibility complex (MHC)-II; clone M5/114.15.2], CX3CR1 (clone SA011F11), Ly6C (clone HK1.4), and Ly6G (clone 1A8) antibodies (BioLegend) were used to perform the flow cytometry. Cells were analyzed on a BD LSR II cytometer (BD Biosciences, San Jose, CA) using FlowJo software version 10.4.2 (Tree Star, Ashland, OR).

\section{Quantification of Immunohistochemistry}

Macroglia were quantified using ImageJ version $1.5 \mathrm{~s}$, on whole eye tissue cross sections stained with DAPI and glial fibrillary acidic protein monoclonal antibody, at indicated times after injury. Different time points were selected for analysis. For each time point, three different tissue sections from three different mice $(n=3)$ were used. The area of interest was marked using the freehand selection tool, according to DAPI boundaries. The enclosed area was measured $\left(\mathrm{mm}^{2}\right)$, and the image was decomposed to red and blue channels. The red and blue channels that corresponded to glial fibrillary acidic protein and DAPI expression, respectively, were selected and converted to binary information. The positive pixels (bright pixels) were quantified, the outcome was normalized according to the total sampled area, and the resulting number was plotted. Microglia quantification was also performed in retinal flat mounts of CX3CR $1^{+/ E G F P}$ mice. The three distinct retinal layers known to be occupied by tissue resident microglia [ganglion cell layer (GCL), inner plexiform layer, and outer plexiform layer] were analyzed. The longest cell process length, which is a marker of cell quiescence, was used as a morphometric descriptor to analyze microglia activation. RNFL quantification was performed in flat mount retinas. The red channel that corresponded to $\beta 3$-tubulin expression was selected and converted to binary information. The positive pixels (bright pixels) were quantified, the outcome was normalized according to the total sampled area, and the resulting number was plotted.

\section{Statistical Analysis}

Results were analyzed with the Statistical Package of Social Sciences Version 17.0 (SPSS Inc., Chicago, IL). The normality of continuous variables was assessed using the

\footnotetext{
Figure 4 Monocyte infiltration into the retina after corneal burn. Image quantification of CX3CR1 ${ }^{+}$and CCR2 ${ }^{+}$cell infiltration in the retina after corneal alkali burn using CX3CR1::CCR2 ${ }^{\text {EGFP/RFP }}$ bone marrow (BM) chimera. A, F, and G: In naive mice, only few ramified CX3CR1 $1^{+}$CCR2 ${ }^{-}$cells are present around the optic nerve head (ONH). These cells do not migrate beyond its boundary. However, scant CX3CR1 ${ }^{-}$CCR2 ${ }^{+}$cells are found across the retina, located in the ganglion cell layer (GCL). B: Twenty-four hours after corneal surface injury, amoeboid CX3CR1 ${ }^{+} \mathrm{CCR} 2^{+}$cells from the blood infiltrate the retina and locate themselves primarily in the $\mathrm{GCL}$. An increased number of amoeboid CX3CR1 ${ }^{+}$CCR2 ${ }^{+}$cells is present around the $0 \mathrm{NH}$ (white arrows) and along the retinal vessels (red arrows). Only a few cells are CX3CR1 ${ }^{+}$CCR2 ${ }^{-}$. C, F, and G: At 24 hours, anti-tumor necrosis factor (TNF)- $\alpha$ treatment (TX) reduces the infiltration of blood-derived CX3CR1 ${ }^{+}$CCR2 ${ }^{+}$cells in the retina. D, F, and G: At day 7, infiltrated blood-derived CX3CR1 ${ }^{+}$CCR2 ${ }^{+}$cells accumulate between the $\mathrm{GCL}$ and outer nuclear layer (0NL) and exhibit a phenotypic differentiation from amoeboid to dendritiform. The number of blood-derived CX3CR1 ${ }^{+} \mathrm{CCR} 2^{+}$cells in the GCL and inner plexiform layer remains elevated, whereas a significant number of CCR2 ${ }^{+}$cells are located around the outer segment of the ONH (white arrow). E-G: TNF- $\alpha$ inhibition reduces the number of peripheral $\mathrm{CX} 3 \mathrm{CR}^{+}{ }^{+} \mathrm{CCR} 2^{+}$cell infiltrates and promotes differentiation from amoeboid to dendritiform morphology and concomitant abolishment of CCR2 marker. CCR2 remains expressed by amoeboid cells. H: Flow cytometry in CX3CR1 ${ }^{+/ E G F P}$ BM chimeras confirms the reduction in CX3CR1 ${ }^{+}$cell infiltration after anti-TNF- $\alpha$ treatment. $\mathbf{F}$ and $\mathbf{G}$ : Independent group comparisons with naive mouse as reference using Holm-Sidak method. $n=6$ per group (F and $\mathbf{G}) ; n=3$ per group $(\mathbf{H}) .{ }^{*} P<0.05,{ }^{* \star * *} P<0.0001$ versus naive. Scale bars $=100 \mu \mathrm{m}(\mathbf{A}-\mathbf{E})$. BMT, BM transfer; EGFP, enhanced green fluorescent protein.
} 


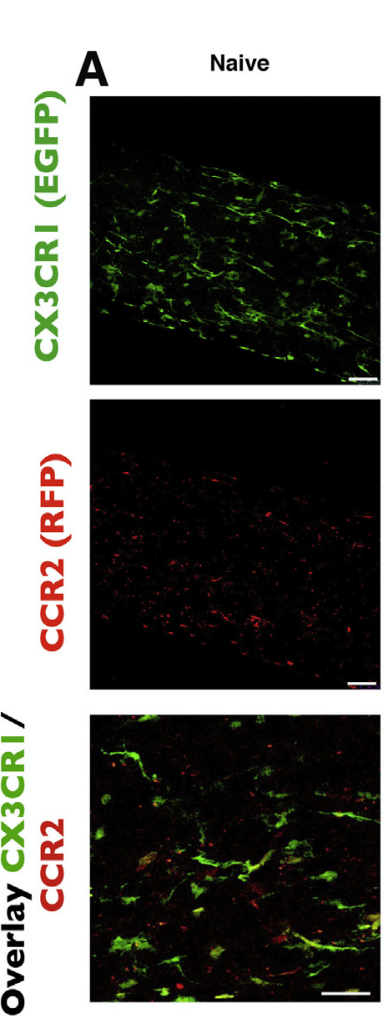

10 weeks after BMT
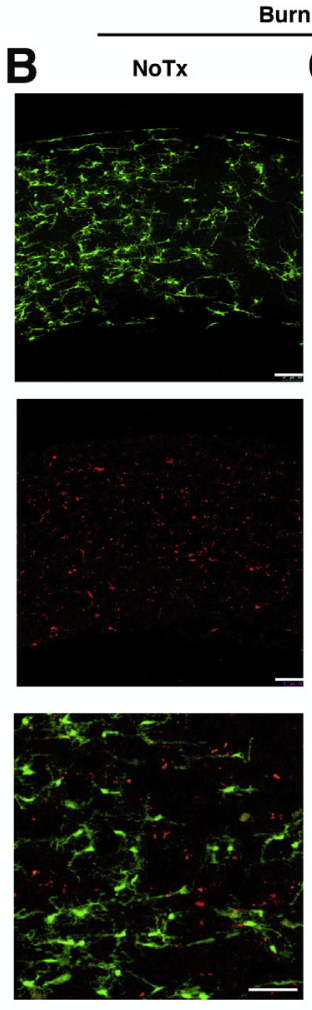

10 weeks after BMT
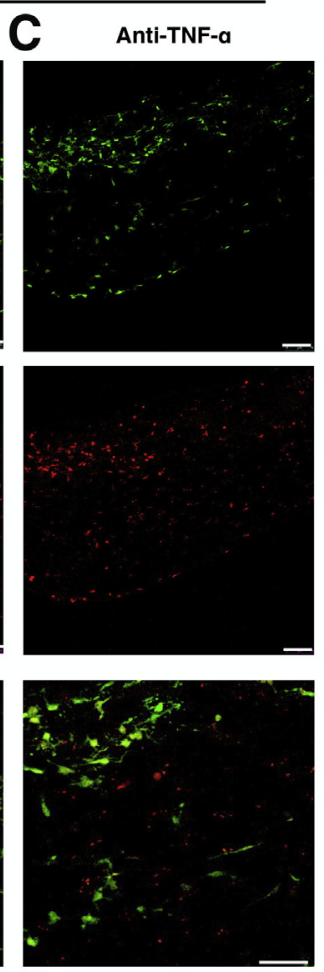

10 weeks after BMT

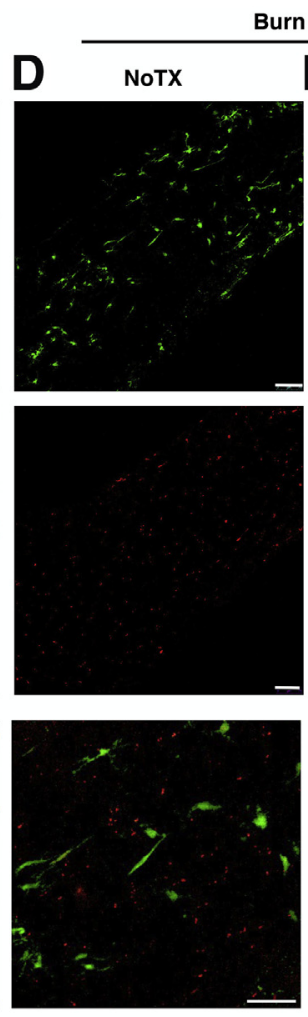

11 weeks after BMT urn 7 days
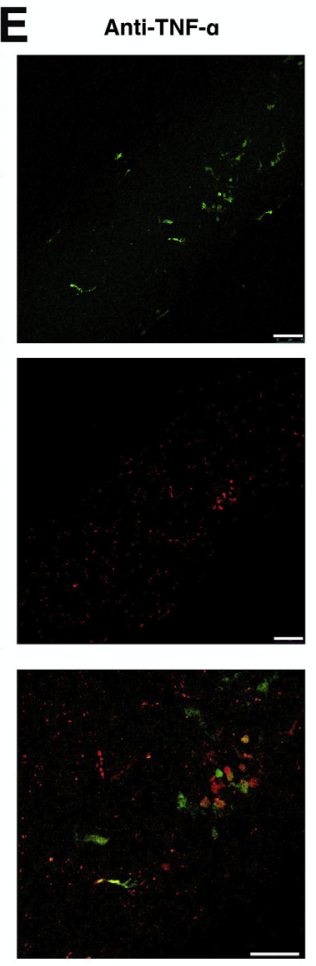

11 weeks after BMT
$\mathbf{F}$

G

\section{CX3CR1}

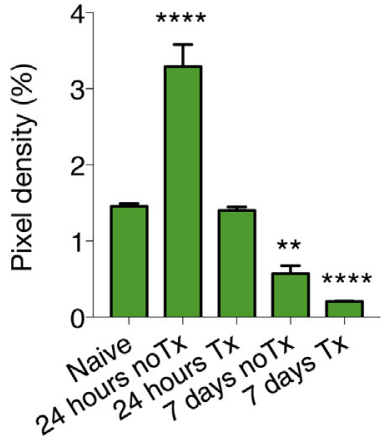

CCR2

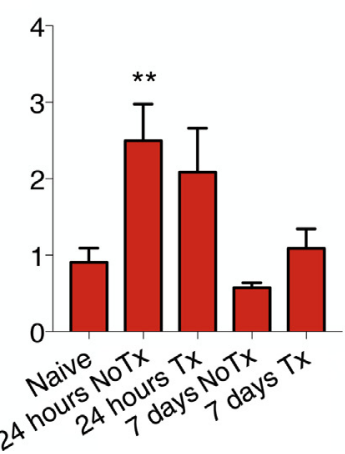

Figure 5 Monocyte infiltration into the retina through the optic nerve head. Image quantification of $\mathrm{CX} 3 \mathrm{CR}_{1}{ }^{+} \mathrm{CCR}^{+}$cell infiltration in the optic nerve (ON) after corneal alkali burn using CX3CR1 ${ }^{+/ E G F P}:: C C R 2^{+/ R F P}$ bone marrow (BM) chimera model. A-E: Confocal microscopy of ONs of BMtransferred (BMT) mice. A, F, and $\mathbf{G}$ : Blood-derived $\mathrm{CX} 3 \mathrm{CR} 1^{+}$and $\mathrm{CCR2}^{+}$ cells physiologically populate the $\mathrm{ON}$ within 10 weeks after BMT. Most cells are either $\mathrm{CX} 3 \mathrm{CR} 1^{+} \mathrm{CCR} 2^{-}$or $\mathrm{CX} 3 \mathrm{CR} 1^{-}{ }^{-} \mathrm{CR} 2^{+}$, with only few cells expressing both markers. CX3CR1 ${ }^{+} \mathrm{CCR} 2^{-}$and $\mathrm{CX} 3 \mathrm{CR} 1^{+} \mathrm{CCR} 2^{+}$acquire a semiramified morphology, whereas $\mathrm{CX} 3 \mathrm{CR} 1^{-} \mathrm{CCR} 2^{+}$are mainly amoeboid in appearance. B, D, F, and G: Twenty-four hours after corneal alkali burn, CX3CR1/CCR2 cell numbers increase in the optic nerves, followed by gradual reduction at 7 days $(P<0.005)$. C and $\mathbf{E}-\mathbf{G}$ : Anti-tumor necrosis factor (TNF)- $\alpha$ treatment (Tx) significantly reduces the number of $\mathrm{CX} 3 \mathrm{CR} 1 / \mathrm{CCR} 2^{+}$cells in the $0 \mathrm{~N} 24$ hours and 7 days after the burn, and leads to reduction in the number of migrating cells into the retina. $\mathbf{F}$ and $\mathbf{G}$ : Independent group comparisons with naive mouse as reference using Holm-Sidak method. $n=3$ per group ( $\mathbf{F}$ and $\mathbf{G})$. ${ }^{* *} P<0.01,{ }^{* * * *} P<0.0001$ versus naive. Scale bars $=75 \mu \mathrm{m}(\mathbf{A}-\mathbf{E})$.

\section{Results}

expressed as means \pm SEM, and qualitative variables were expressed as frequencies and percentages. The Mann-Whitney test was used to assess differences between the groups. All tests were two-tailed, and statistical significance was determined at $P<0.05$. The independent $t$-test was used to compare between two groups, and pairwise $t$-test was used to compare changes within the same group. Analysis of variance was used for comparison of multiple groups. $\alpha$ Level correction was applied, as appropriate, for multiple comparisons.

\section{Corneal Alkali Burn Leads to Retinal Damage in Humans and Animals}

Corneal alkali injury causes severe corneal scarring and neovascularization in patients (Figure $1 \mathrm{~A}$ ) and advanced cupping and pallor of the optic nerve (ON) (Figure 1B). The latter cannot be explained alone by typical intraocular pressure-induced glaucomatous damage. ${ }^{2,3}$ In vivo retinal 
analysis using optical coherence tomography typically reveals significant loss of neuroretinal tissue and thinning of the RNFL in all retinal quadrants, similar to that seen in end-stage glaucoma (Figure 1C). Corneal alkali burns in animals, such as rabbits or mice, result in phenotypical changes similar to human burns, including severe corneal scarring and neovascularization (Figure 1, D and $\mathrm{H}$ ), progressive loss of $\beta 3$ tubulin ${ }^{+}$neuroretinal tissue, thinning of the RNFL (Figure 1, E and I), and $\mathrm{ON}$ axon degeneration (Figure $1, \mathrm{~F}$ and $\mathrm{J}$ ), without intraocular pressure elevation or chemical diffusion posteriorly. ${ }^{4-6}$ Within 3 months of the injury, the retinas of rabbits and mice exhibit a significant 40\% RGC loss (Figure 1, G and K). Microarray analysis in retinal tissues of burned mice showed marked up-regulation of a range of inflammatory genes within 24 hours of the burn (Figure 1L). In particular, significant up-regulation (more than twofold change $\log _{2}$ ) was found in chemokine (C-C motif) ligands 2, 6, 7, and 12 and receptors CCR 1, 2, 3, and 5, which are responsible for monocyte recruitment and signal transduction. ${ }^{23}$ Up-regulation of colony stimulating factor 1 gene, which is essential for microglia survival, was also noted. ${ }^{24}$ Chemokine (C-X-C motif) ligands 1, 5 , and 10 and receptor $\mathrm{Cxcr} 2$ genes ${ }^{25-28}$ were also up-regulated, as well as inflammatory mediators of the IL and tumor necrosis factor- $\alpha$ families (Figure $1 \mathrm{~L}$ ).

\section{Microglia Activation and Blood-Derived Monocyte Infiltration after Ocular Injury}

To investigate the inflammatory cellular components of retinal damage, two major immune cell populations involved in acute inflammatory response (the microglia and the bloodderived monocytes) were studied. Microglia are the resident tissue phagocytes of the retina, expressing $\mathrm{CX} 3 \mathrm{C}$ chemokine receptor 1 (CX3CR1). ${ }^{29}$ On activation, they undergo morphologic and biochemical changes, characterized by shortening of their dendritic processes and assuming a more amoeboid shape.

Corneal injury led to morphometric $\mathrm{CX} 3 \mathrm{CR} 1^{+}$cell activation in the GCL at 24 hours and in all retinal layers (GCL, inner nuclear layer, outer plexiform layer) at 7 days (Figure 2, A and B). Cell activation was associated with significant shortening of the cell process length and uniaxial elongation of cell body in the direction of the nerve fiber layer (Figure 2A). An increased number of amoeboid CX3CR $1^{+}$cells were found around the outer segment of the $\mathrm{ON}$ head (ONH) and the RNFL (Figure 2C and Supplemental Video S1). Treatment with TNF- $\alpha$ inhibitor prevented $\mathrm{CX} 3 \mathrm{CR} 1^{+}$cell activation and improved morphometric ramification in the GCL and inner nuclear layer compared with vehicle control (Figure 2, A and B). In addition, anti-TNF- $\alpha$ treatment reduced the accumulation of $\mathrm{CX} 3 \mathrm{CR} 1^{+}$cells around the outer segment of the $\mathrm{ONH}$ (Figure 2C and Supplemental Figure S1).

Because CX3CR1 is a marker of both resident microglia and peripheral monocyte/macrophages, flow cytometry was performed to differentiate and analyze the two cell populations. MHC-II marker was used to assess activation. $\mathrm{CX} 3 \mathrm{CR} 1^{+} \mathrm{CD} 45^{\text {hi }} \mathrm{CD} 11 \mathrm{~b}^{+}$cells were used to define bloodborne macrophages, and $\mathrm{CX} 3 \mathrm{CR} 1^{+} \mathrm{CD} 45^{\mathrm{lo}} \mathrm{CD} 11 \mathrm{~b}^{+}$cells were used for microglia. ${ }^{14,30-32}$ MHC-II marker was used to assess cell activation. ${ }^{3 .}$

Retinal cells from CX3CR $1^{+/ E G F P}$ mice were analyzed with flow cytometry. Two distinct CX3CR $1^{+}$cell populations were identified: $\mathrm{CX} 3 \mathrm{CR} 1^{+} \mathrm{CD} 11 \mathrm{~b}^{+} \mathrm{CD} 45^{\mathrm{hi}}$ (macrophages) and $\mathrm{CX} \mathrm{CR} 1^{+} \mathrm{CD} 1 \mathrm{~b}^{+} \mathrm{CD} 5^{\text {lo }}$ (microglia) (Figure 3). In naive eyes, most $\mathrm{CX} 3 \mathrm{CR} 1^{+}$cells were $\mathrm{CD} 45^{\text {lo }}$, with no MHC-II expression. A negligible $(<0.1 \%)$ fraction of $\mathrm{CX} 3 \mathrm{CR} 1^{+}$ cells were CD $45^{\text {hi }}$ but did not express MHC-II (Figure 3). At 24 hours after the injury, the percentage of $\mathrm{CX} 3 \mathrm{CR} 1^{+} \mathrm{CD} 11 \mathrm{~b}^{+}$ $\mathrm{CD} 45^{\text {hi }}$ cells increased with concomitant increase in the number of MHC-II ${ }^{+}$cells from 1500 to $100,000 \mathrm{MHC}^{-\mathrm{II}^{+}}$ cells/retina $(P=0.002)$ (Figure 3$)$. At the same time, the percentage of $\mathrm{CX} 3 \mathrm{CR} 1^{+} \mathrm{CD} 11 \mathrm{~b}^{+} \mathrm{CD} 45^{\text {lo }}$ cells reduced slightly, without significant change in the number of $\mathrm{MHC}-\mathrm{II}^{+}$ cells $(P>0.999)$ (Figure 3$)$.

Seven days after the burn, the percentage of CX3CR $1^{+}$ $\mathrm{CD}_{11 \mathrm{~b}^{+}} \mathrm{CD}^{\mathrm{hi}} 5^{\mathrm{hi}}$ cells was reduced, with concomitant reduction in the number of $\mathrm{MHC}-\mathrm{II}^{+}$cells from 100,000 to $20,000{\mathrm{MHC}-\mathrm{II}^{+}}^{+}$cells/retina $(P<0.005)$. At the same time, the percentage of $\mathrm{CX} 3 \mathrm{CR} 1^{+} \mathrm{CD} 11 \mathrm{~b}^{+} \mathrm{CD} 45^{\text {lo }}$ cells

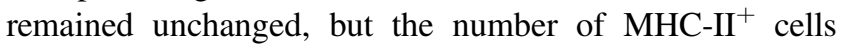
increased from 900 to $15,000(P<0.0001)$ (Figure 3).

Anti-TNF- $\alpha$ treatment significantly reduced the number of activated $\mathrm{CX} 3 \mathrm{CR} 1^{+} \mathrm{CD} 11 \mathrm{~b}^{+} \mathrm{CD} 45^{\mathrm{hi}} \mathrm{MHC}-\mathrm{II}^{+}$ cells at 24 hours from 100,000 to 38,000 cells/retina $(P<0.01)$ but did not affect the number of CX3CR $1^{+}$ CD45 ${ }^{\text {lo }} \mathrm{CD}_{11 \mathrm{~b}^{+}} \mathrm{MHC}^{\mathrm{II}}{ }^{+}$cells $(P=0.807)$ (Figure 3 ). At 7 days, anti-TNF- $\alpha$ treatment increased the expression of $\mathrm{CX} 3 \mathrm{CR} 1^{+} \mathrm{CD} 45^{\text {1o }} \mathrm{CD} 11 \mathrm{~b}^{+}$cells and their corresponding MHC-II expression $(P=0.014)$, but had no effect on the number of $\mathrm{CX} 3 \mathrm{CR} 1^{+} \mathrm{CD} 45^{\mathrm{hi}} \mathrm{CD} 11 \mathrm{~b}^{+}$ MHC-II ${ }^{+}$cells $(P>0.999)$ (Figure 3$)$. Overall, anti-TNF- $\alpha$ treatment reduced early infiltration of bloodderived monocytes and subsequent MHC-II activation of these cells.

\section{Blood-Derived CX3CR1 ${ }^{+}$CCR2 ${ }^{+}$Monocytes Rapidly Infiltrate into the Retina after Corneal Alkali Injury}

To understand the role of blood-derived monocyte infiltration in retinal damage, a bone marrow chimera model with fluorescent labeled CCR2 $2^{+/ R F P}$ and CX3CR $1^{+/ E G F P}$ cells was used. Busulfan myelodepletion was performed instead of $\gamma$ radiation, to prevent radiation-induced blood-retina barrier disruption and subsequent infiltration of monocytes. Briefly, bone marrow cells from $\mathrm{CCR} 2^{+/ \mathrm{RFP}}:: \mathrm{CX} 3 \mathrm{CR} 1^{+/ \text {EGFP }}$ mice were harvested and transferred to busulfan myelodepleted C57BL/6 wild-type mice. At 4 weeks, bone marrow engraftment reached $95 \%$ efficiency, as determined by flow cytometry (data not shown).

In naive mice, a small number of dendritiform CCR2 ${ }^{-}$ $\mathrm{CX} 3 \mathrm{CR} 1^{+}$cells were found around the ONH 10 weeks after 
A

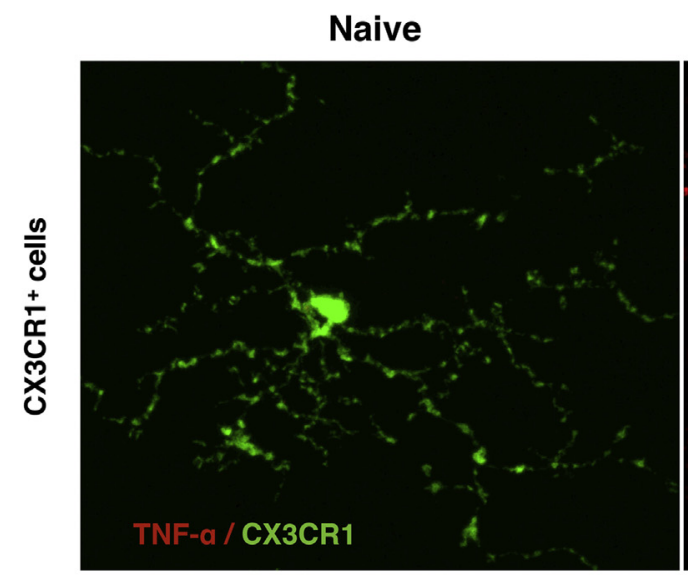

B
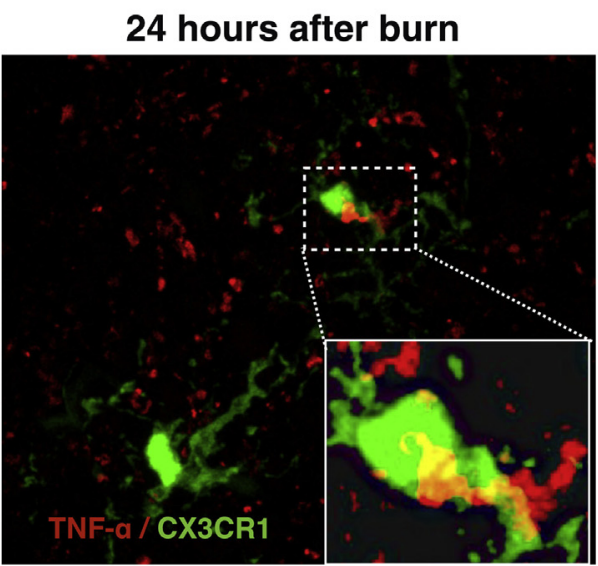

C
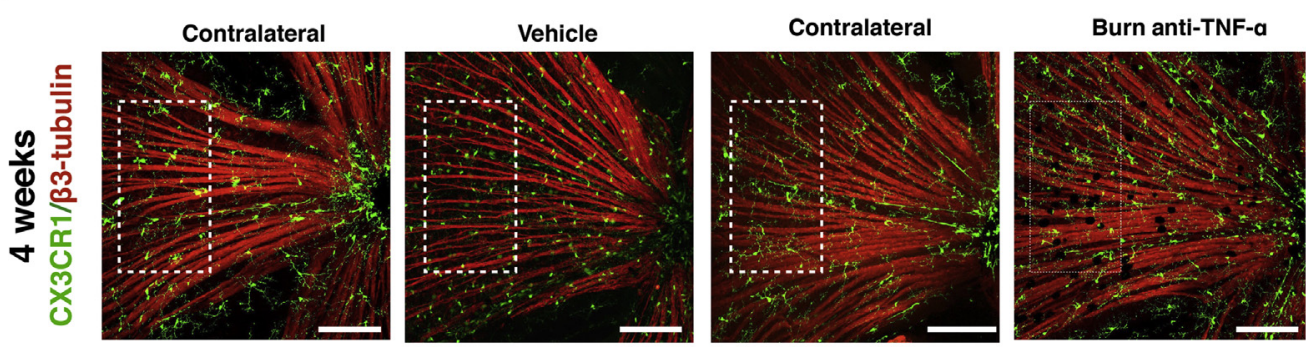

D

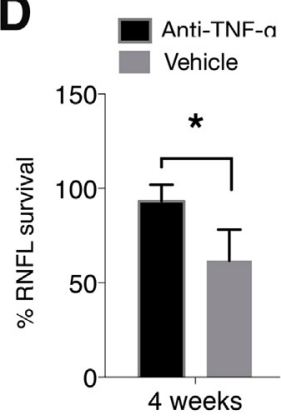

E

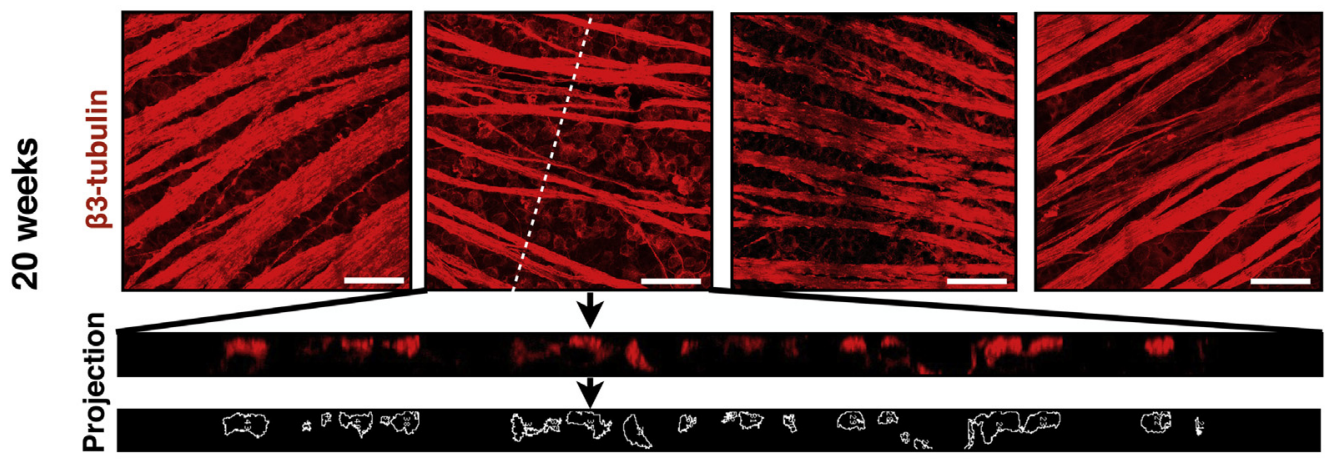

$\mathbf{F}$

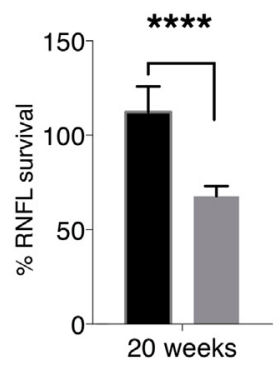

G

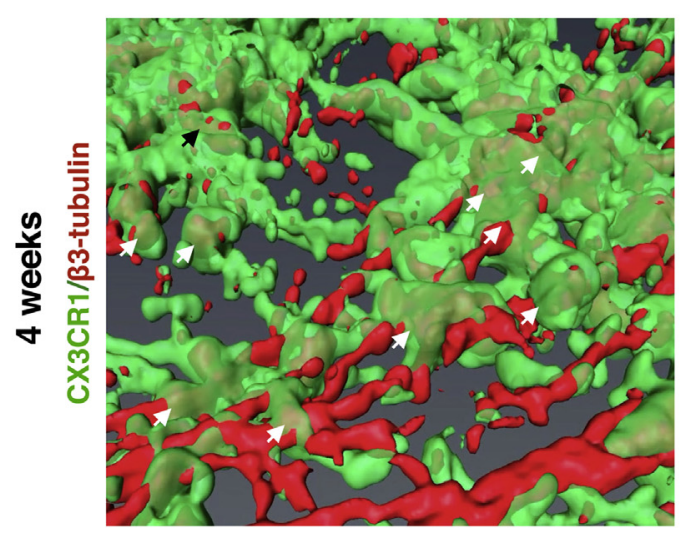

H

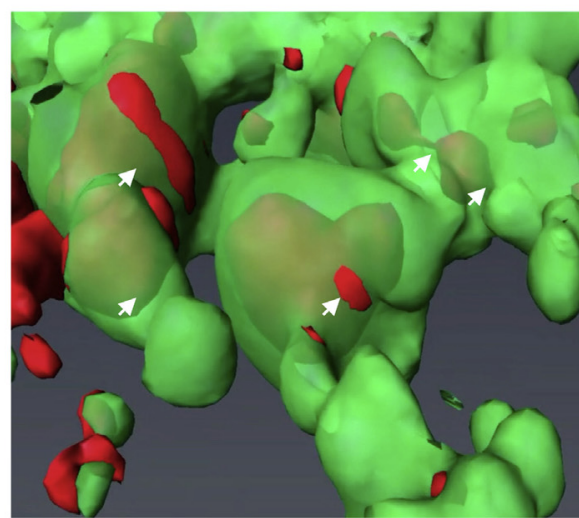


bone marrow transfer. However, these cells did not appear to migrate beyond the $\mathrm{ONH}$ boundary (Figure $4 \mathrm{~A}, \mathrm{~F}$, and G). A few amoeboid CCR2 ${ }^{+} \mathrm{CX} 3 \mathrm{CR} 1^{-}$cells were found across the entire GCL (Figure 4A and Supplemental Figure S1). Twenty-four hours after the injury, CCR2 ${ }^{+}$ CX3CR $1^{+}$cells had accumulated into the retina and around the ONH. Cell infiltration into the retina appeared to occur through the $\mathrm{ONH}$, and infiltrated cells appeared to align along the retinal vessels (Figure 4, B and F-H). Infiltrated CCR2 ${ }^{\text {hi }} \mathrm{CX} 3 \mathrm{CR} 1^{\text {lo }}$ cells were highly amoeboid in shape (Figure 2, B and C) and scattered homogeneously across the GCL (Figure 4B and Supplemental Figure S1). At 7 days, the number of infiltrated $\mathrm{CCR} 2^{+} \mathrm{CX} 3 \mathrm{CR} 1^{+}$cells increased within the GCL and inner plexiform layer (Figure $4 B$ and Supplemental Figure S1), and appeared to adopt a more ramified morphology, expressing $\mathrm{CCR} 2^{\text {hi }} \mathrm{CX} 3 \mathrm{CR} 1^{\text {hi }}$ (Figure 4, D, F, and G).

Using flow cytometry, the inhibitory effect of anti-TNF$\alpha$ treatment on $\mathrm{CX} 3 \mathrm{CR} 1^{+}$cell infiltration into the retina 24 hours and 7 days after the burn was confirmed (Figure $4 \mathrm{H}$ ). In addition to reducing $\mathrm{CCR} 2^{+} \mathrm{CX} 3 \mathrm{CR} 1^{+}$cell infiltration 24 hours and 7 days after the burn, anti-TNF- $\alpha$ treatment facilitated cell differentiation from amoeboid to dendritiform, and shifted their expression from CCR2 ${ }^{\text {hi }} \mathrm{CX} 3 \mathrm{CR} 1^{-/ \mathrm{lo}}$ to $\mathrm{CCR} 2^{-/ \mathrm{lo}} \mathrm{CX} 3 \mathrm{CR} 1^{\mathrm{hi}}$ at 7 days (Figure $4, \mathrm{C}$ and $\mathrm{E}-\mathrm{G}$ ).

Further analysis of monocyte infiltration in the $\mathrm{ON}$ was performed with confocal microscopy. Peripheral CCR2 ${ }^{+}$ CX3CR $1^{+}$cells were shown to physiologically populate the ON within 4 weeks after bone marrow transfer. Most of the cell infiltrates were either $\mathrm{CCR} 2^{\text {hi }} \mathrm{CX} 3 \mathrm{CR} 1^{\text {lo }}$ or $\mathrm{CCR} 2^{\text {lo }}$ CX3CR $1^{\text {hi }}$ (Figure 5). Fewer cells simultaneously expressed CCR2 and CX3CR1 markers. CCR $2^{\text {hi }} \mathrm{CX} 3 \mathrm{CR} 1^{\text {lo }}$ cells were mostly amoeboid, whereas CCR2 $2^{\text {lo }}$ CX3CR $1^{\text {hi }}$ cells were ramified, with some rare exceptions (Figure 5). Corneal alkali burn appeared to increase CX3CR1 and CCR2 expression in the ON 24 hours after the injury, and anti-TNF- $\alpha$ treatment appeared to inhibit this increase (Figure 5). Collectively, these results suggest that both the retinal and ON CCR2 ${ }^{+}$ $\mathrm{CX} 3 \mathrm{CR} 1^{+}$cells respond to the corneal injury within 24 hours, and that TNF- $\alpha$ blockade appears to affect both tissues.

\section{Activated Neuroglia and Blood Monocytes Promote Neuroinflammation and Degeneration}

Using immunofluorescence, it was found that 24 hours after the burn, CX3CR1 $1^{+}$cells in the GCL express TNF- $\alpha$
(Figure 6, A and B). Flow cytometry of CX3CR::CCR2 $2^{\text {EGFP/RFP }}$ mice confirmed TNF- $\alpha$ expression from $\mathrm{CD} 45^{\text {lo }} \mathrm{CCR}^{-}$(microglia) $^{31}$ and $\mathrm{CD} 45^{\text {hi }} \mathrm{CCR}^{+}$ (peripheral monocytes) $^{31}$ (Figure 7, A and B). Furthermore, peripheral $\mathrm{CX} 3 \mathrm{CR} 1^{+} \mathrm{CCR}^{+}$monocytes and $\mathrm{CX} 3 \mathrm{CR} 1^{+}$ CCR2 ${ }^{-}$microglia expressed activation marker MHC-II, with monocytes expressing higher levels of MHC-II than microglia (Figure 7, C-E). These data suggest that monocytes respond more vigorously to the injury than microglia.

Inflammation after burn was associated with significant neuronal tissue loss at both 4 and 20 weeks after the injury. Neuronal dropout was abrogated by TNF- $\alpha$ inhibition (Figure 6, C-F).

Interestingly, activated $\mathrm{CX} 3 \mathrm{CR} 1^{+}$cells were spatially juxtaposed with $\beta 3$-tubulin, and they appeared to phagocytose neuronal tissue (Figure 6, G and $\mathrm{H}$, and Supplemental Video S2).

\section{Discussion}

This study aims to improve our understanding of the enigmatic retinal damage that follows acute corneal chemical burns. Clinical findings in patients experiencing ocular chemical injuries often show not only corneal and anterior chamber changes, but also glaucoma, with frequent relentless progression to end-stage blindness, despite efforts to prevent or slow down the process. ${ }^{2,3}$

This early retinal damage is not mediated by intraocular pressure elevation or posterior diffusion of the alkali itself in mice and rabbits; the preretinal vitreous $\mathrm{pH}, \mathrm{O}_{2}$, and oxidation-reduction levels remain normal 24 hours after the burn, ${ }^{4}$ suggesting that the iris and the lens act as barriers to further chemical diffusion posteriorly through the vitreous body. The alkali is unable to diffuse posteriorly through the suprachoroidal space 24 hours after the burn. ${ }^{4}$ Rather, rapid changes in $\mathrm{pH}$, oxidation-reduction, and $\mathrm{O}_{2}$ levels are restricted to the cornea, anterior chamber, and iris. These changes lead to a massive up-regulation of inflammatory cytokines in the anterior chamber, such as TNF- $\alpha$ and IL-1 $\beta$, that rapidly diffuse posteriorly to the retina. ${ }^{4}$ Within 24 hours of the burn, retinal CD45 ${ }^{+}$immune cells become activated and promote additional TNF- $\alpha$ synthesis. ${ }^{4}$ The inflammatory response in the retina is sustained for weeks and months after the injury, triggering further RGC loss. ${ }^{4}$ This hypothesis is further supported by the strong neuroprotective effect of infliximab, a TNF- $\alpha$ inhibitor, which

\footnotetext{
Figure 6 Activated neuroglia and blood monocytes promote neuroinflammation and degeneration. A and B: Tumor necrosis factor (TNF)- $\alpha$ staining in flatmounted CX3CR1 ${ }^{+/ E G F P}$ mouse retinas. CX3CR1 and TNF- $\alpha$ markers are coexpressed in the ganglion cell layer 24 hours after the burn. B: Inset: Magnification of the dotted boxed area. C and D: Four weeks after the burn, CX3CR1 ${ }^{+}$cells (green) remain activated (amoeboid), and the retinal nerve fiber layer ( $\beta I I I-t u b u l i n ;$ red) exhibits $40 \%$ tissue density loss $(P<0.05)$ compared with treatment with anti-TNF- $\alpha$ antibody that abrogates CX3CR1 ${ }^{+}$cell activation (less amoeboid) and inhibits retinal nerve fiber layer (RNFL) loss. Dotted boxed areas represent the section of the retina nerve fiber layer that was used for quantification. E and F: Quantification of RNFL thickness using vertical projection analysis of flat-mounted retinas 20 weeks after the burn shows $40 \%$ RNFL loss $(P<0.0001)$, compared with anti-TNF- $\alpha$ treated mice. The dotted line represents the location of the cross-sectional cut for quantification. $\mathbf{G}$ and $\mathbf{H}$ : Three-dimensional rendering of a retina flat mount shows amoeboid CX3CR1 ${ }^{+}$cells (semitransparent green) appearing to ensheathe (white arrows) $\beta 3$-tubulin ${ }^{+}$neuronal tissue (red) 4 weeks after corneal alkali burn. $\mathbf{D}$ and $\mathbf{F}$ : Independent group comparisons using Holm-Sidak method. $n=3$ per group (D and $\mathbf{F})$. ${ }^{*} P<0.05$, $* * * * P<0.0001$. Scale bars $=50 \mu \mathrm{m}(\mathbf{C}$ and $\mathbf{E})$. Original magnification: $\times 63(\mathbf{A}, \mathbf{B}$, and $\mathbf{H}) ; \times 40(\mathbf{G})$.
} 
A

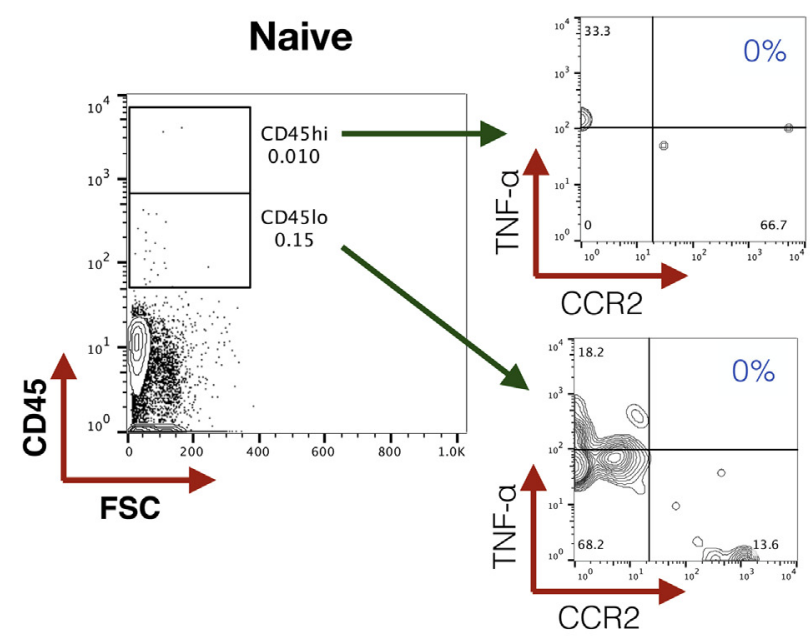

C

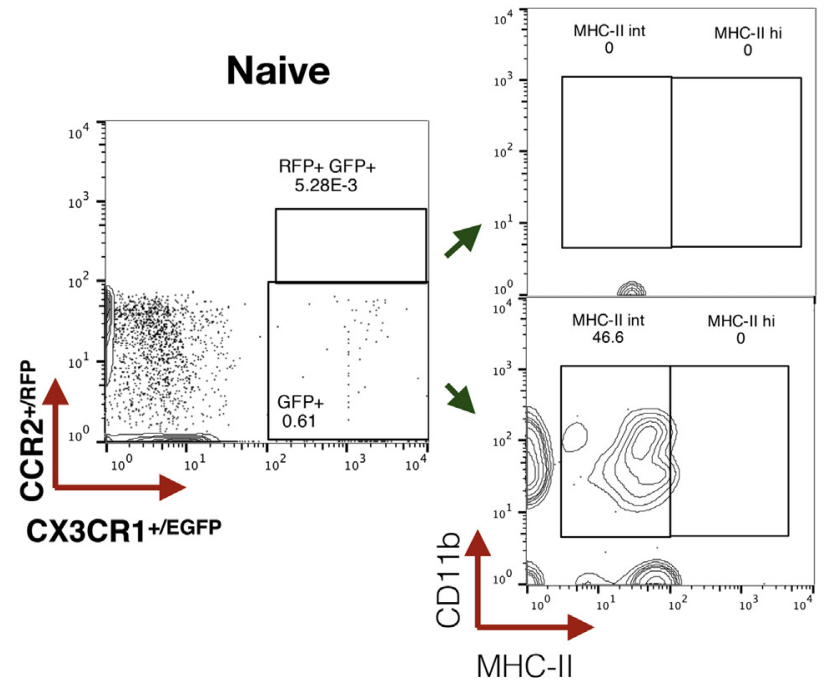

B

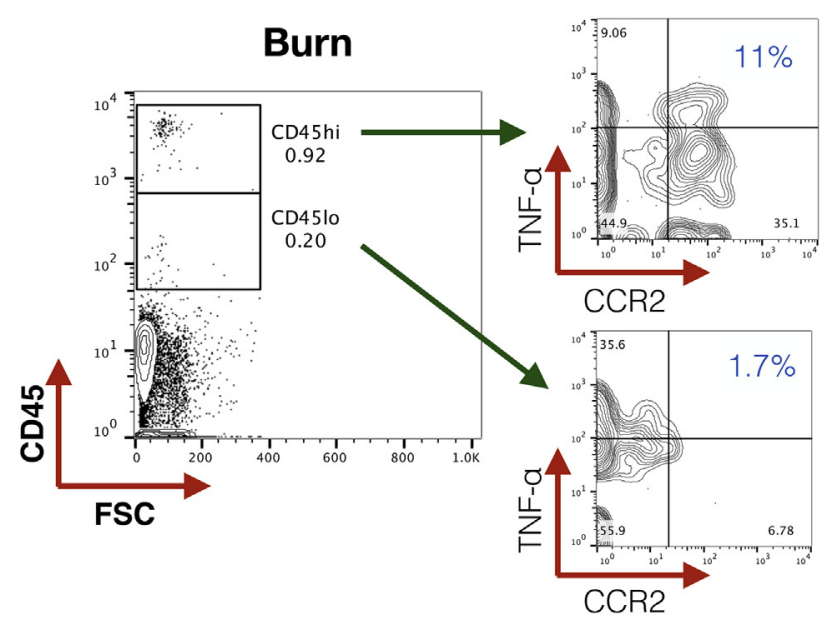

D

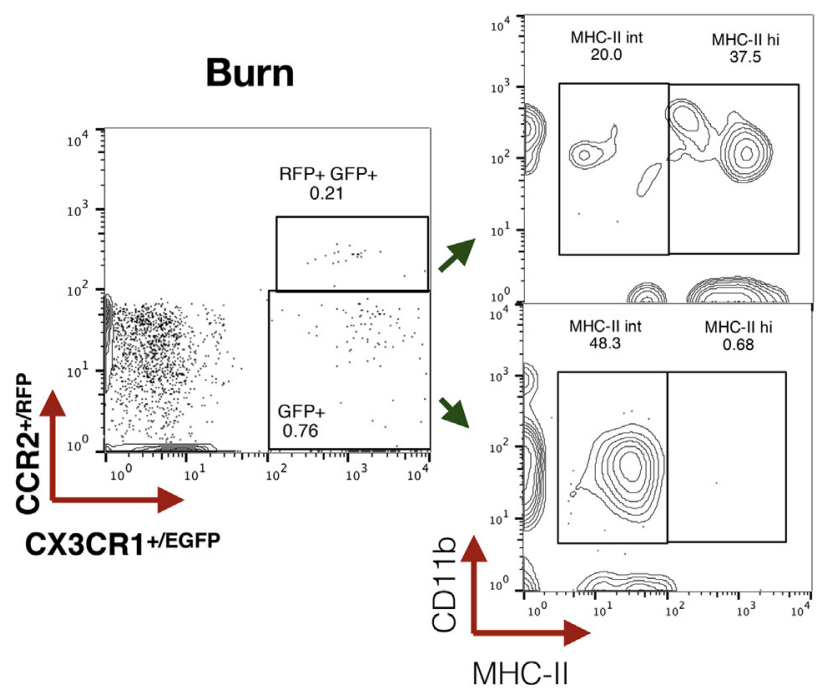

$\mathbf{E}$

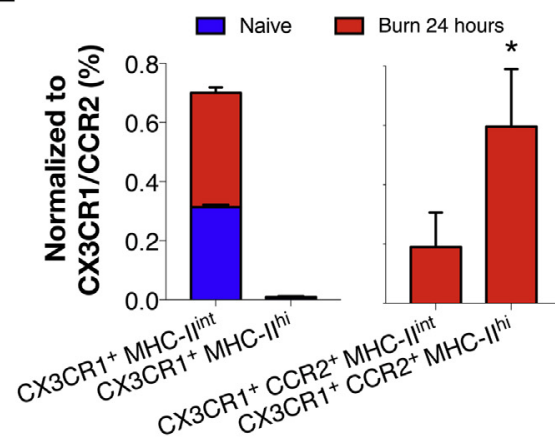

Figure $7 \quad \mathrm{CX} 3 \mathrm{CR}^{+}{ }^{+} \mathrm{CCR}^{+}$monocyte activation and tumor necrosis factor (TNF)- $\alpha$ expression in the retina. Flow cytometry of $\mathrm{CX} 3 \mathrm{CR} 1$ :: $\mathrm{CCR} 2^{\mathrm{EGFP} / \mathrm{RFP}}$ mice. $\mathbf{A}$ and $\mathbf{B}$ : 0 cular injury increases the percentage of $\mathrm{CD} 45^{\text {hi }} \mathrm{CCR2}^{+}$cells in the retina at 24 hours. TNF- $\alpha$ is expressed by $\mathrm{CD}_{4} 5^{\text {lo }} \mathrm{CCR}^{-}{ }^{-}$(microglia) and $\mathrm{CD} 45^{\text {hi }} \mathrm{CCR}^{+}$(peripheral monocytes). C-E: At 24 hours after ocular surface injury, peripheral CX3CR1 ${ }^{+} \mathrm{CCR}^{+}$monocytes are shown to express high levels of activation marker major histocompatibility complex (MHC)-II ${ }^{\text {hi }}$. The ocular burn has no significant effect on MHC-II expression by CX3CR1 ${ }^{+}$CCR2 ${ }^{-}$microglia, which remain at low levels $\left(\mathrm{MHC}-\mathrm{II}^{\text {int }}\right)$. Independent group comparisons between naive and burn 24 hours using analysis of variance and Holm-Sidak method. $n=3$ in all groups. ${ }^{*} P<0.05$ verus naive (unpaired $t$-test). FSC, forward scatter; GFP, green fluorescent protein; RFP, red fluorescent protein. prevents RGC loss and retinal damage, if administered promptly after the burn. ${ }^{4,5,21}$

Building on the results of our prior studies, ${ }^{4,5,21}$ the role of two major $\mathrm{CD} 45^{+}$immune cell populations (the retinal microglia and peripheral monocytes/macrophages) was investigated. Microglia have become the focus of intense scientific investigation because of their specialized functions. ${ }^{8,34,35}$ In mice and humans, microglia are the principal nonneuronal cells of the CNS, ${ }^{10,35}$ involved in tissue homeostasis, immune defense, and neuroplasticity. $8,14,34-36$ The retina is populated by microglia during early embryogenesis ${ }^{8,37-39}$ but is devoid of blood-derived 
A

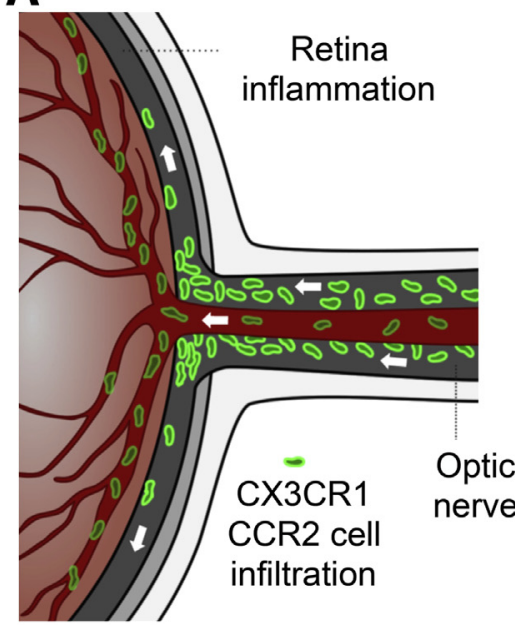

B

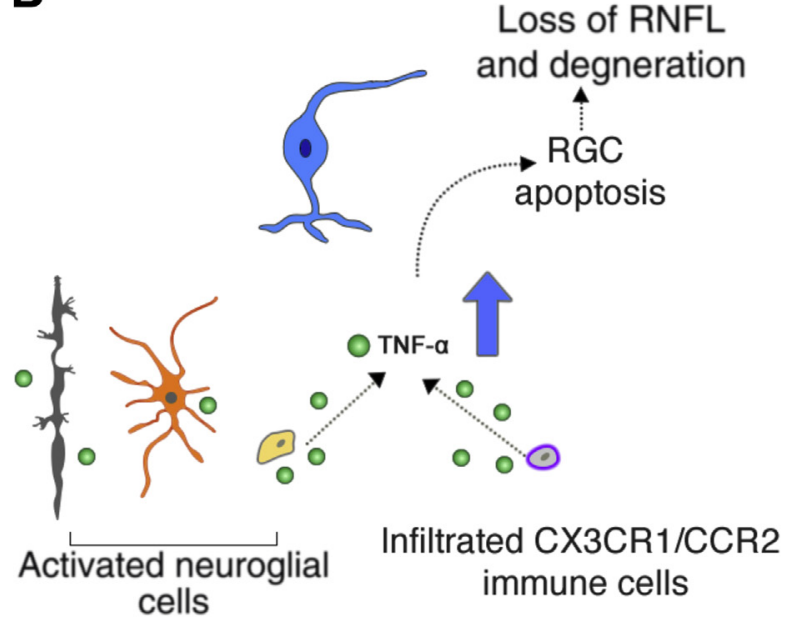

Figure 8 Proposed mechanism of retinal damage after corneal alkali burn. The effect of blood-derived monocytes and neuroglia in retinal degeneration after acute ocular surface trauma with alkali. A: Corneal alkali injury causes acute retinal inflammation and infiltration of CX3CR1 ${ }^{+}$and CCR2 ${ }^{+}$cells through the optic nerve head that align along the retinal vessels. B: Increased monocyte/macrophage trafficking causes neuroglial cell activation and subsequent elevation of inflammation. Activated CX3CR1 ${ }^{+}$cells enswathe retinal ganglion cells (RGCs) and nerve axons, a gliotic process that leads to retinal tissue damage. RNFL, retinal nerve fiber layer; TNF- $\alpha$, tumor necrosis factor- $\alpha$.

macrophages. ${ }^{12-14}$ Pathologic conditions, including TNF- $\alpha$-mediated inflammation, may cause macrophages to enter into the retina. ${ }^{40,41}$ Given that microglia and myeloid macrophages share a common lineage, distinction between the two cell populations is difficult. Herein, modern cell analysis techniques and bone marrow chimeras were used to study the two cell populations. ${ }^{33}$

Two chronologically distinct waves of retinal cell death were previously identified after a corneal chemical burn: an early wave at 24 hours and a late one at 7 days after the injury. ${ }^{5}$ The injury was primarily located at the GCL. ${ }^{4,5}$ Herein, it was shown that the first wave of retinal damage coincides with peripheral monocyte infiltration, whereas the late phase is associated with microglia activation. Acute peripheral monocyte infiltration and microglia activation occur primarily in the GCL, which corresponds to the location of the observed damage. ${ }^{4,5}$ Although direct TNF- $\alpha$ diffusion from the injured anterior segment may cause RGC damage, ${ }^{5}$ it may also activate neuroglia and monocytes to release further TNF- $\alpha$ locally. ${ }^{15,42-44}$ From this study, it is not clear if microglia activation was protective or deleterious to the neuroretina; both peripheral monocytes and microglia secreted TNF- $\alpha$ on activation. However, microglia activation represents a danger signal that should be considered. ${ }^{15}$ In previous studies, microglia activation was shown to occur only in highly pathologic states ${ }^{45}$ and could be beneficial, deleterious, or neutral. ${ }^{15}$ Further studies using microglia depletion methods may help understand the specific roles peripheral monocytes and microglia play in retinal damage.

An important finding of this study is the ability of peripheral CCR2 ${ }^{+} \mathrm{CX} 3 \mathrm{CR} 1^{+}$monocytes to replenish the tissue resident macrophages of the optic nerve but not of the retina under steady-state conditions. Blood-derived $\mathrm{CX}_{3} \mathrm{CR} 1^{+}$cells were shown to physiologically populate the $\mathrm{ON}$ but were unable to migrate beyond the $\mathrm{ONH}$ boundary into the retina. Presumably, local cellular interactions at the $\mathrm{ONH}$ inhibit further migration. ${ }^{23,26,46}$ However, under inflammatory conditions, these cells migrated into the retina through the ONH. Possibly, the $\mathrm{ON}$ acts as an intermediate pool of tissue resident macrophages for the retina, which can be recruited if needed. It is plausible that the local environment in the ON could promote the maturation and differentiation of peripheral monocytes to acquire functions required for neuronal surveillance. Monocytes in the ON adopt a dendritiform appearance soon after bone marrow transfer, and these cells down-regulate the monocyte marker CCR2. A previous study, however, showed that bone marrow-derived brain macrophages do not adapt to the CNS environment, because 7 days after entry, they retain expression signatures similar to peripheral myeloid cells. ${ }^{47}$ It is possible that transcriptional reprogramming may require longer residency times. Also, the conditions under which cell infiltration occurs may determine the transcriptional fate of these cells. For example, in the former study, ${ }^{47}$ monocyte infiltration in the brain occurred in a setting of blood-brain barrier disruption because of myelodepletion from $\gamma$-irradiation, as opposed to the likely preserved retinal blood barrier of busulfan myelodepleted mice in this study. Herein, busulfan myelodepletion and bone marrow transfer did not cause infiltration of blood-derived monocytes in the retina, but caused infiltration for the ON, suggesting that the observed infiltration is not an artifact. Overall, the retina and $\mathrm{ON}$ appeared to possess different regulatory mechanisms for infiltration of blood-derived monocytes, 
despite their physical proximity and membership to the CNS. Moreover, this finding may suggest that other CNS compartments differ as well. ${ }^{47,48}$ An up-regulation of C-C and $\mathrm{C}-\mathrm{X}-\mathrm{C}$ motif signals was observed in the retina 24 hours after the burn, which may facilitate infiltration/ migration of monocytes in the retina. In addition, the possibility of peripheral monocyte infiltration directly through the retina vasculature should not be excluded; increased numbers of myeloid CX3CR $1^{+}$cells were present along the retinal vessels after the injury.

Interestingly, the presence of patrolling $\mathrm{CX} 3 \mathrm{CR} 1^{+}$cells in the retina, as previously proposed, was not observed. ${ }^{49}$ Possibly, the use of sublethal $\gamma$ irradiation for myelodepletion in the earlier study led to blood-retinal barrier disruption and subsequent infiltration of $\mathrm{CX} 3 \mathrm{CR} 1^{+}$monocytes into the retina that appeared as patrolling cells. ${ }^{14,45,47}$ Busulfan myelodepletion, which was previously shown not to disrupt the blood-brain-barrier, was used in this study. ${ }^{41}$ These results were corroborated, and it was found that 10 weeks after bone marrow transfer, no myeloid cells were present in the retina. Rather, patrolling CCR2 ${ }^{+} \mathrm{CX} 3 \mathrm{CR} 1^{-}$ monocytes were detected in the retina that differentiated to $\mathrm{CCR} 2^{+} \mathrm{CX}_{3} \mathrm{CR} 1^{+}$monocytes after the injury. CCR $2^{+}$ CX3CR1 $1^{-}$cells are preferentially recruited into injured tissue, ${ }^{31}$ and CCR2 ${ }^{+}$Ly6C ${ }^{\text {hi }}$ cells have been suggested to contribute to microglia turnover in the brain. ${ }^{13}$ In the current study, CCR2 ${ }^{+}$cells had no contribution to retinal microglia turnover under physiological conditions, but they contributed to rapid population of the retina by peripheral CCR2 ${ }^{+}$ $\mathrm{CX}_{3} \mathrm{CR}^{+}$monocytes that gradually differentiated to microglia-like dendritiform $\mathrm{CCR} 2^{-} \mathrm{CX} 3 \mathrm{CR} 1^{+}$cells after the injury.

The importance of TNF- $\alpha$ in neuroglia activation and subsequent neuroretinal inflammation is well recognized. ${ }^{4-6,15,20,42-44,50,51}$ This study validates and reaffirms the critical role of TNF- $\alpha$ blockade in retinal neuroprotection. Ocular surface injury leads to $\mathrm{C}-\mathrm{C}$ and $\mathrm{C}-\mathrm{X}-\mathrm{C}$ motif chemokine up-regulation in the retina and subsequent peripheral monocyte recruitment. Monocytes secrete TNF$\alpha$, which causes secondary activation of microglia and further release of TNF- $\alpha$. This process leads to neurodegeneration that can be inhibited by blocking the TNF- $\alpha$ pathway. A single i.p. injection of monoclonal TNF- $\alpha$ inhibitor significantly reduces peripheral monocyte infiltration in the retina and microglia activation, resulting in retinal neuroprotection. These findings corroborate our previously published results in chemical burns and support the use of TNF- $\alpha$ inhibitors in burn patients. ${ }^{4-6,21}$

In conclusion, this study provides a plausible mechanism to explain the immunological processes that lead to retinal damage after acute corneal alkali injury. A link between the anterior and posterior segments that includes the retina and the $\mathrm{ON}$ is demonstrated. Furthermore, the involvement of microglia and peripheral monocytes in the inflammatory process is highlighted. Also, it was determined that $\mathrm{ON}$ and retina differ in peripheral monocyte regulation, where infiltrating monocytes/macrophages play a key role in early-phase retinal damage, whereas microglia play an important role in the late phase. In summary, ocular surface injury leads to recruitment of peripheral monocytes, up-regulation of inflammatory mediators, subsequent activation of microglia, and irreversible retinal damage (Figure 8). These findings may also prove relevant to other neurodegenerative diseases of the retina and the central nervous system.

\section{Acknowledgments}

E.I.P. designed the study, conducted experiments, acquired and analyzed data, and wrote the manuscript; F.L., C.Z., V.K., and A.T. conducted experiments, acquired and analyzed data, and reviewed the manuscript; D.G.V., R.D., J.C., and C.H.D. critically reviewed the manuscript.

\section{Supplemental Data}

Supplemental material for this article can be found at https://doi.org/10.1016/j.ajpath.2018.03.005.

\section{References}

1. Smith RE, Conway B: Alkali retinopathy. Arch Ophthalmol 1976, 94: $81-84$

2. Cade F, Grosskreutz CL, Tauber A, Dohlman CH: Glaucoma in eyes with severe chemical burn, before and after keratoprosthesis. Cornea 2011, 30:1322-1327

3. Crnej A, Paschalis EI, Salvador-Culla B, Tauber A, DrnovsekOlup B, Shen LQ, Dohlman CH: Glaucoma progression and role of glaucoma surgery in patients with Boston keratoprosthesis. Cornea 2014, 33:349-354

4. Paschalis EI, Zhou C, Lei F, Scott N, Kapoulea V, Robert MC, Vavvas D, Dana R, Chodosh J, Dohlman CH: Mechanisms of retinal damage after ocular alkali burns. Am J Pathol 2017, 187: $1327-1342$

5. Cade F, Paschalis EI, Regatieri CV, Vavvas DG, Dana R, Dohlman CH: Alkali burn to the eye: protection using TNF- $\alpha$ inhibition. Cornea 2014, 33:382-389

6. Zhou C, Robert M-C, Kapoulea V, Lei F, Stagner AM, Jakobiec FA, Dohlman CH, Paschalis EI: Sustained subconjunctival delivery of infliximab protects the cornea and retina following alkali burn to the eye. Invest Ophthalmol Vis Sci 2017, 58:96-105

7. Kim SU, de Vellis J: Microglia in health and disease. J Neurosci Res 2005, 81:302-313

8. Block ML, Zecca L, Hong J-S: Microglia-mediated neurotoxicity: uncovering the molecular mechanisms. Nat Rev Neurosci 2007, 8: $57-69$

9. Dheen ST, Kaur C, Ling E-A: Microglial activation and its implications in the brain diseases. Curr Med Chem 2007, 14: 1189-1197

10. Prinz M, Priller J: Microglia and brain macrophages in the molecular age: from origin to neuropsychiatric disease. Nat Rev Neurosci 2014, $15: 300-312$

11. Rice RA, Spangenberg EE, Yamate-Morgan H, Lee RJ, Arora RPS, Hernandez MX, Tenner AJ, West BL, Green KN: Elimination of microglia improves functional outcomes following 
extensive neuronal loss in the hippocampus. J Neurosci 2015, 35 : 9977-9989

12. Ajami B, Bennett JL, Krieger C, Tetzlaff W, Rossi FMV: Local selfrenewal can sustain CNS microglia maintenance and function throughout adult life. Nat Neurosci 2007, 10:1538-1543

13. Mildner A, Schmidt H, Nitsche M, Merkler D, Hanisch U-K, Mack M, Heikenwalder M, Brück W, Priller J, Prinz M: Microglia in the adult brain arise from Ly-6ChiCCR2+ monocytes only under defined host conditions. Nat Neurosci 2007, 10: $1544-1553$

14. Kettenmann H, Hanisch U-K, Noda M, Verkhratsky A: Physiology of microglia. Physiol Rev 2011, 91:461-553

15. Ransohoff RM, Brown MA: Innate immunity in the central nervous system. J Clin Invest 2012, 122:1164-1171

16. Inman DM, Horner PJ: Reactive nonproliferative gliosis predominates in a chronic mouse model of glaucoma. Glia 2007, 55:942-953

17. Bosco A, Steele MR, Vetter ML: Early microglia activation in a mouse model of chronic glaucoma. J Comp Neurol 2011, 519: 599-620

18. Hanisch U-K, Kettenmann H: Microglia: active sensor and versatile effector cells in the normal and pathologic brain. Nat Neurosci 2007, 10:1387-1394

19. Tezel G, Li LY, Patil RV, Wax MB: TNF-alpha and TNF-alpha receptor-1 in the retina of normal and glaucomatous eyes. Invest Ophthalmol Vis Sci 2001, 42:1787-1794

20. Roh M, Zhang Y, Murakami Y, Thanos A, Lee SC, Vavvas DG, Benowitz LI, Miller JW: Etanercept, a widely used inhibitor of tumor necrosis factor- $\alpha$ (TNF- $\alpha$ ), prevents retinal ganglion cell loss in a rat model of glaucoma. PLoS One 2012, 7:e40065

21. Dohlman CH, Cade F, Regatieri CV, Zhou C, Lei F, Crnej A, HarissiDagher M, Robert M-C, Papaliodis GN, Chen D, Aquavella JV, Akpek EK, Aldave AJ, Sippel KC, D'Amico DJ, Dohlman JG, Fagerholm P, Wang L, Shen LQ, Gonzalez-Andrades M, Chodosh J, Kenyon KR, Foster CS, Pineda R, Melki S, Colby KA, Ciolino JB, Vavvas DG, Kinoshita S, Dana R, Paschalis EI: Chemical burns of the eye: the role of retinal injury and new therapeutic possibilities. Cornea 2018, 37:248-251

22. Committee for the Update of the Guide for the Care and Use of Laboratory Animals; National Research Council: Guide for the Care and Use of Laboratory Animals: Eighth Edition. Washington, DC, National Academies Press, 2011

23. Le Y, Zhou Y, Iribarren P, Wang J: Chemokines and chemokine receptors: their manifold roles in homeostasis and disease. Cell Mol Immunol 2004, 1:95-104

24. Erblich B, Zhu L, Etgen AM, Dobrenis K, Pollard JW: Absence of colony stimulation factor-1 receptor results in loss of microglia, disrupted brain development and olfactory deficits. PLoS One 2011, 6: e26317

25. Tsai HH, Frost E, To V, Robinson S, Ffrench-Constant C, Geertman R, Ransohoff RM, Miller RH: The chemokine receptor CXCR2 controls positioning of oligodendrocyte precursors in developing spinal cord by arresting their migration. Cell 2002, 110:373-383

26. Pelus LM, Fukuda S: Peripheral blood stem cell mobilization: the CXCR2 ligand GRObeta rapidly mobilizes hematopoietic stem cells with enhanced engraftment properties. Exp Hematol 2006, 34:1010-1020

27. Boivin N, Menasria R, Gosselin D, Rivest S, Boivin G: Impact of deficiency in CCR2 and CX3CR1 receptors on monocytes trafficking in herpes simplex virus encephalitis. J Gen Virol 2012, 93: $1294-1304$

28. Arnoux I, Audinat E: Fractalkine signaling and microglia functions in the developing brain. Neural Plast 2015, 2015:689404

29. Salter MW, Stevens B: Microglia emerge as central players in brain disease. Nat Med 2017, 23:1018-1027

30. Mittal R, Gonzalez-Gomez I, Panigrahy A, Goth K, Bonnet R, Prasadarao NV: IL-10 administration reduces PGE-2 levels and promotes CR3-mediated clearance of Escherichia coli K1 by phagocytes in meningitis. J Exp Med 2010, 207:1307-1319
31. Mizutani M, Pino PA, Saederup N, Charo IF, Ransohoff RM, Cardona AE: The fractalkine receptor but not CCR2 is present on microglia from embryonic development throughout adulthood. J Immunol 2012, 188:29-36

32. Hambardzumyan D, Gutmann DH, Kettenmann H: The role of microglia and macrophages in glioma maintenance and progression. Nat Neurosci 2015, 19:20-27

33. Berman NE, Marcario JK, Yong C, Raghavan R, Raymond LA, Joag SV, Narayan O, Cheney PD: Microglial activation and neurological symptoms in the SIV model of NeuroAIDS: association of MHC-II and MMP-9 expression with behavioral deficits and evoked potential changes. Neurobiol Dis 1999, 6: 486-498

34. Wynn TA, Chawla A, Pollard JW: Macrophage biology in development, homeostasis and disease. Nature 2013, 496:445-455

35. Sajja VSSS, Hlavac N, VandeVord PJ: Role of glia in memory deficits following traumatic brain injury: biomarkers of glia dysfunction. Front Integr Neurosci 2016, 10:5311

36. Sun D, Lye-Barthel M, Masland RH, Jakobs TC: Structural remodeling of fibrous astrocytes after axonal injury. J Neurosci 2010, 30: 14008-14019

37. Ginhoux F, Greter M, Leboeuf M, Nandi S, See P, Gokhan S, Mehler MF, Conway SJ, Ng LG, Stanley ER, Samokhvalov IM, Merad M: Fate mapping analysis reveals that adult microglia derive from primitive macrophages. Science 2010, 330:841-845

38. Kierdorf K, Erny D, Goldmann T, Sander V, Schulz C, Perdiguero EG, Wieghofer P, Heinrich A, Riemke P, Holscher C, Muller DN, Luckow B, Brocker T, Debowski K, Fritz G, Opdenakker G, Diefenbach A, Biber K, Heikenwalder M, Geissmann F, Rosenbauer F, Prinz M: Microglia emerge from erythromyeloid precursors via Pu.1- and Irf8-dependent pathways. Nat Neurosci 2013, 16:273-280

39. Crotti A, Ransohoff RM: Microglial physiology and pathophysiology: insights from genome-wide transcriptional profiling. Immunity 2016, 44:505-515

40. Guadagno J, Xu X, Karajgikar M, Brown A, Cregan SP: Microgliaderived TNF|[alpha] induces apoptosis in neural precursor cells via transcriptional activation of the Bcl-2 family member Puma. Cell Death Dis 2013, 4:e538

41. Kierdorf K, Katzmarski N, Haas CA, Prinz M: Bone marrow cell recruitment to the brain in the absence of irradiation or parabiosis bias. PLoS One 2013, 8:e58544

42. Bezzi P, Domercq M, Brambilla L, Galli R, Schols D, De Clercq E, Vescovi A, Bagetta G, Kollias G, Meldolesi J, Volterra A: CXCR4-activated astrocyte glutamate release via $\mathrm{TNF} \alpha$ : amplification by microglia triggers neurotoxicity. Nat Neurosci 2001, 4:702-710

43. Vesce S, Rossi D, Brambilla L, Volterra A: Glutamate release from astrocytes in physiological conditions and in neurodegenerative disorders characterized by neuroinflammation. Int Rev Neurobiol 2007, 82:57-71

44. Rossi D, Volterra A: Astrocytic dysfunction: insights on the role in neurodegeneration. Brain Res Bull 2009, 80:224-232

45. Son JL, Soto I, Oglesby E, Lopez-Roca T, Pease ME, Quigley HA, Marsh-Armstrong N: Glaucomatous optic nerve injury involves early astrocyte reactivity and late oligodendrocyte loss. Glia 2010, 58: 780-789

46. Chinnery HR, Ruitenberg MJ, Plant GW, Pearlman E, Jung S, McMenamin PG: The chemokine receptor CX3CR1 mediates homing of MHC class II-positive cells to the normal mouse corneal epithelium. Invest Ophthalmol Vis Sci 2007, 48:1568-1574

47. Bruttger J, Karram K, Wortge S, Regen T, Marini F, Hoppmann N, Klein M, Blank T, Yona S, Wolf Y, Mack M, Pinteaux E, Muller W, Zipp F, Binder H, Bopp T, Prinz M, Jung S, Waisman A: Genetic cell ablation reveals clusters of local self-renewing microglia in the mammalian central nervous system. Immunity 2015, 43:92-106 
48. Butovsky O, Jedrychowski MP, Moore CS, Cialic R, Lanser AJ, Gabriely G, Koeglsperger T, Dake B, Wu PM, Doykan CE, Fanek Z, Liu L, Chen Z, Rothstein JD, Ransohoff RM, Gygi SP, Antel JP, Weiner HL: Identification of a unique TGF- $\beta$-dependent molecular and functional signature in microglia. Nat Neurosci 2014, 17: $131-143$

49. Kezic J, McMenamin PG: Differential turnover rates of monocytederived cells in varied ocular tissue microenvironments. J Leukoc Biol 2008, 84:721-729
50. Shohami E, Bass R, Wallach D, Yamin A, Gallily R: Inhibition of tumor necrosis factor alpha (TNFalpha) activity in rat brain is associated with cerebroprotection after closed head injury. J Cereb Blood Flow Metab 1996, 16:378-384

51. Nakazawa T, Kayama M, Ryu M, Kunikata H, Watanabe R, Yasuda M, Kinugawa J, Vavvas D, Miller JW: Tumor necrosis factor-alpha mediates photoreceptor death in a rodent model of retinal detachment. Invest Ophthalmol Vis Sci 2011, 52: 1384-1391 